\title{
Employing Service Learning to Promote Student Self-Efficacy in Occupational Therapy Education
}

\author{
Erin E. Schwier \\ University of St. Augustine for Health Sciences \\ DOI: https://doi.org/10.46409/sr.ZQNH2273
}

Follow this and additional works at: https://soar.usa.edu/dissertations

Part of the Higher Education Commons, and the Occupational Therapy Commons

\section{Recommended Citation \\ Schwier, E. E. (2017). Employing Service Learning to Promote Student Self-Efficacy in Occupational Therapy Education. [Doctoral project, University of St Augustine for Health Sciences]. SOAR @ USA: Student Dissertations Collection. https://doi.org/10.46409/sr.ZQNH2273}


Employing Service Learning to Promote Student Self-Efficacy in Occupational Therapy Education

by

Erin E. Schwier

A Dissertation Presented in Partial Fulfillment

Of the Requirements for the Degree

Doctor of Education

University of Saint Augustine

July, 2017 


\section{Employing Service Learning to Promote Student Self-Efficacy in Occupational Therapy Education}

by

Erin E Schwier

has been approved

July 14, 2017

APPROVED:

JUDITH OLSON Ph.D., Faculty Mentor and Chair

ANNE HULL, EdD., Committee Member

ACCEPTED AND SIGNED:

JUDITH OLSON, Ph.D. 


\begin{abstract}
A study was conducted to evaluate student participation in a community-based service learning experience offered in the Masters of Occupational Therapy (OT) Program at the University of St. Augustine for Health Sciences (USAHS) to identify how students' perceptions of their self-efficacy change after they participate in a service-learning experience. A mixed methods case study approach was used to evaluate student's perceptions of self efficacy and identify characteristics of the service learning experience that contribute to improved perceived self-efficacy. A paired samples t test was conducted to compare student confidence levels before and after participation in the service learning project. The analysis of total scores indicates an improvement in confidence after participation in the experiential learning activities offered on each campus. There was a significant difference in the total scores for pretest $(M=460, S D=64.4)$ and posttest $(M=526, S D=54.7)$ in student confidence levels $(t(55)=-9.6, p=.000)$.

Qualitative data indicated that it was the interaction of the prerequisite conditions that created the optimal opportunity for growth and improvement of self-confidence. It is when these opportunities are presented that the development of professional characteristics is facilitated. Through carefully facilitated experiences, and subsequent enhanced professional characteristic development the students then develop core professional attributes. Collectively, the development of these core professional attributes contributes to a greater sense of self-efficacy and improved clinical reasoning for participants. The results of this study were used to construct an emerging educational model that can be used to design educational experiences that will facilitate the
\end{abstract}


development of professional self-efficacy and improved clinical reasoning in occupational therapy students.

It is proposed that the model presented can support occupational therapy educators in the development of curricular experiences that will better support the development of clinical reasoning for occupational therapy students. By emphasizing the development of professional selfefficacy in occupational therapy students, educators can support and maintain the use of occupation as a central philosophy and core value of our profession. By supporting the development of core professional attributes early in education, faculty can support the development of future practitioners who will maintain the use of occupation as the core of our profession, and will ensure that future occupational therapists do continue to use occupation as central to their practice. 
Dedication

For Shadow 


\section{Acknowledgements}

Thank you to everyone who has offered encouragement, support and a little push now and then. When Dr. Wanda Nitsch asked me during my initial interview for full time faculty in 2009 if I was interested in pursuing a terminal degree, I remember answering with an emphatic no. She gave me a knowing nod and said to keep my mind open to the possibility. At the time I thought there was no way after having previously completed a post professional doctorate that it would be of interest to me, or even if I would be capable of the commitment it would take. However she successfully planted the seed, and through the support of the administration at USAHS specifically the guidance of Dr. Cindy Mathena, and the final push from our founding OT program director Dr. Judith Olson, I am happy to say that I did keep my reluctant mind open.

Dr. Olson agreed to chair my dissertation committee, and with the addition of Dr. Anne Hull, director of the institute for occupational therapy at USAHS as second member of my committee, I was able to successfully complete this study. My initial reluctance has now become the potential beginning to what I hope to be a larger contribution to the profession of occupational therapy. A constant support through this process was also the encouragement and inspiration that was provided by the fabulous faculty within the occupational therapy department on the San Marcos campus. Without their passion, drive, and sense of humor none of this would be possible.

And finally without the support and perspective offered by my family none of this process would be even possible. Although they all agree, an additional degree is the last thing I need, they have been a constant supply of support and encouragement. For the last three years, Michael and Xander have supported me through their sacrifices and love. Without my guys this process would not have been possible. 


\section{Table of Contents}

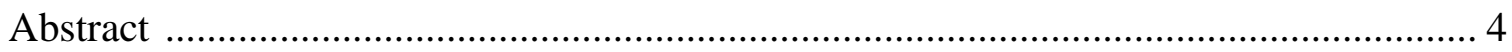

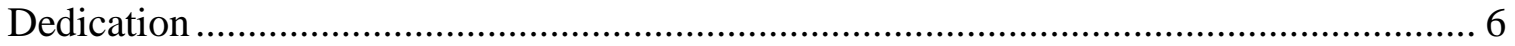

Acknowledgements ......................................................................................... 7

List of Tables and Figures........................................................................................ 10

CHAPTER 1: The Research Problem …………………............................................ 11

Background of the Study ................................................................................. 12

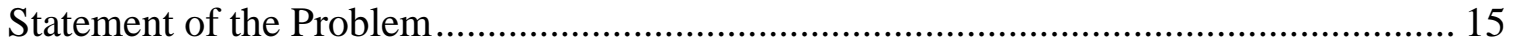

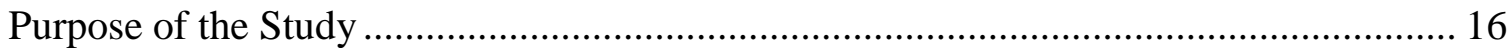

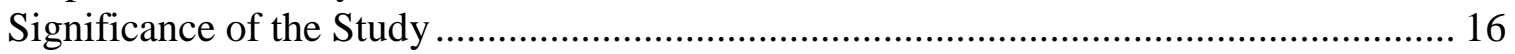

Research Questions ............................................................................................. 17

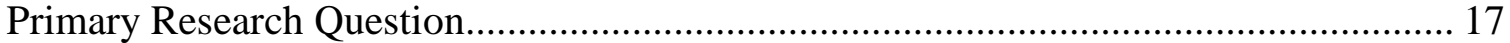

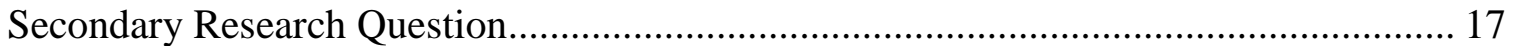

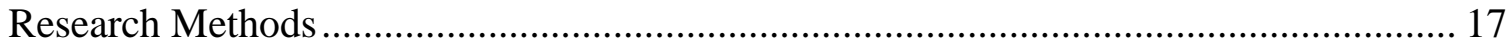

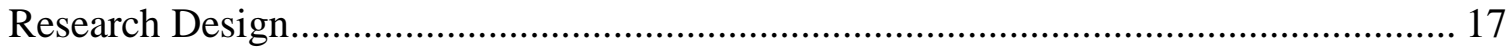

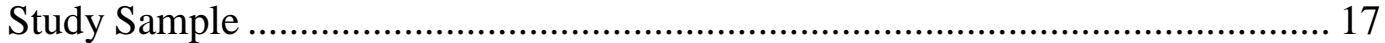

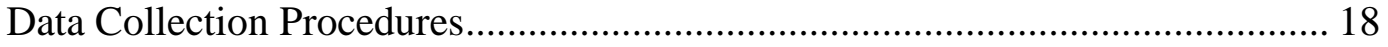

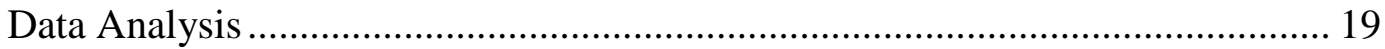

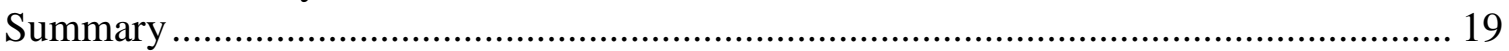

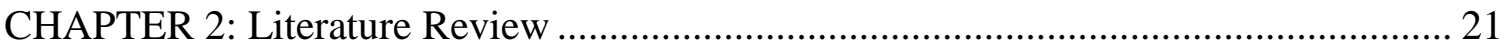

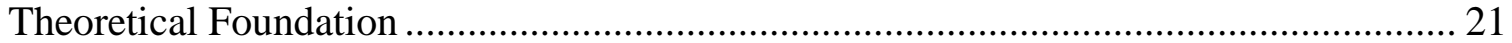

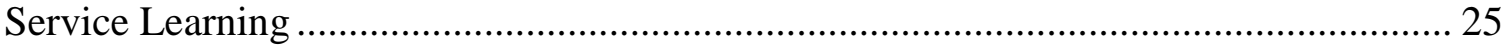

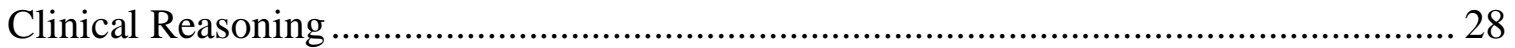

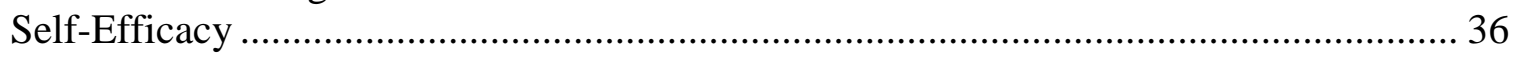

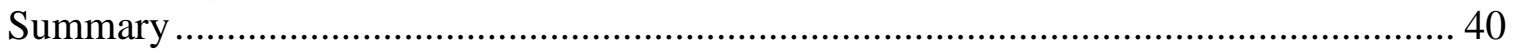

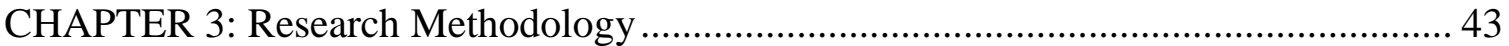

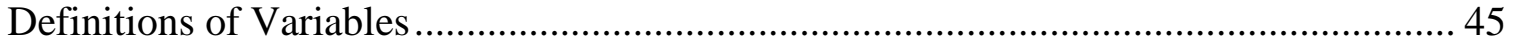

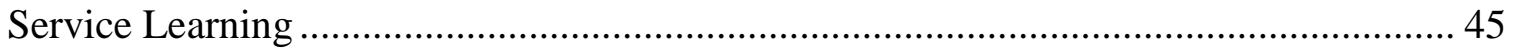

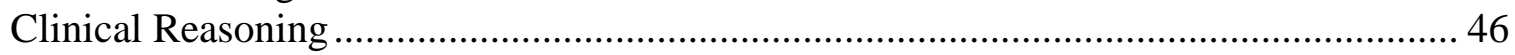

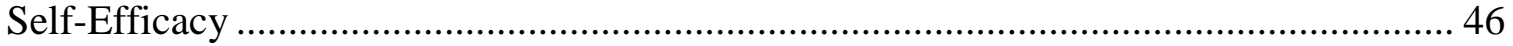

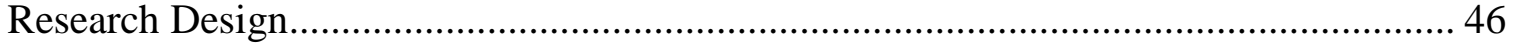

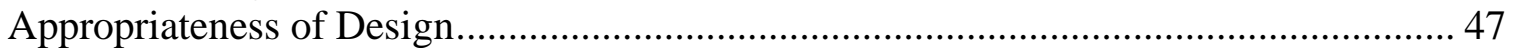

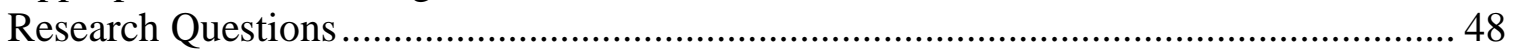

Primary Research Question........................................................................... 48

Secondary Research Question........................................................................... 48

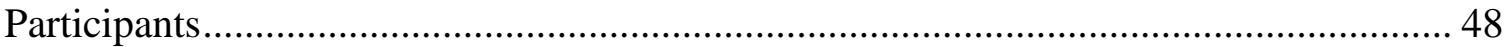

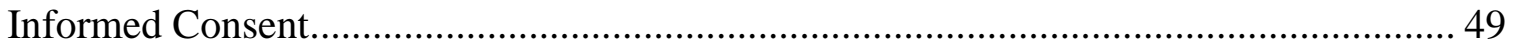

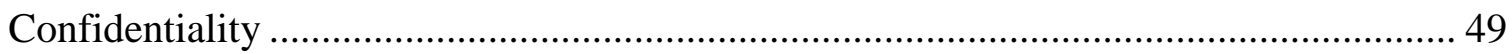

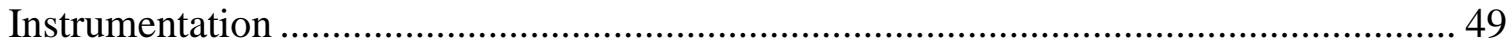

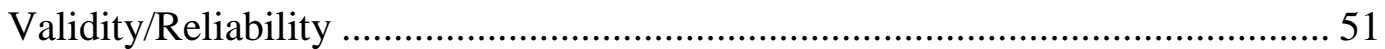

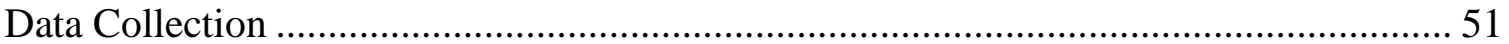

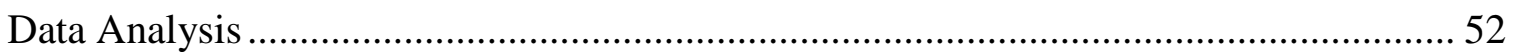

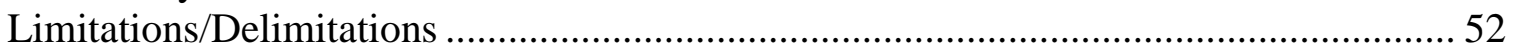

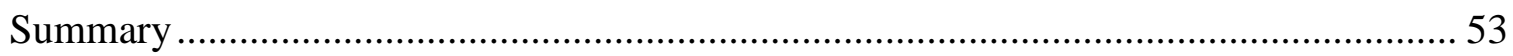

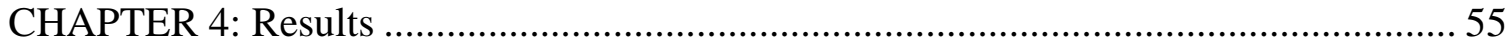

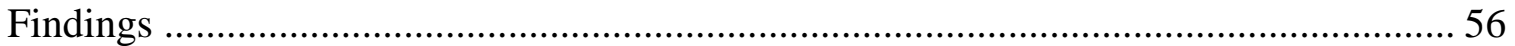

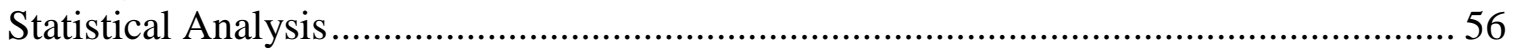

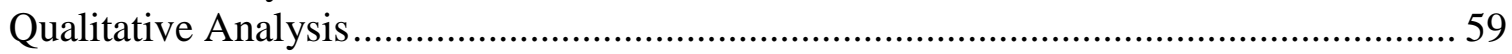

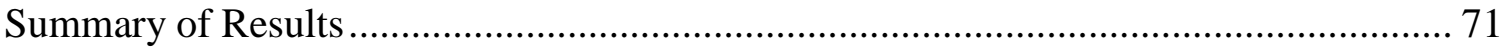




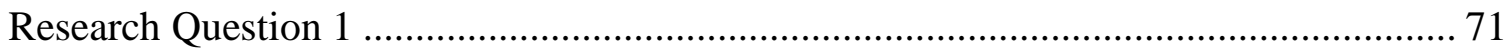

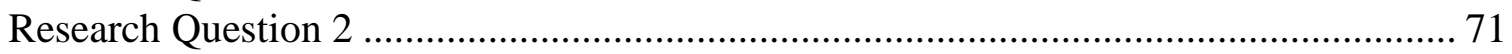

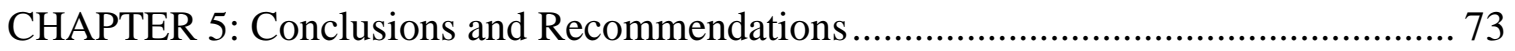

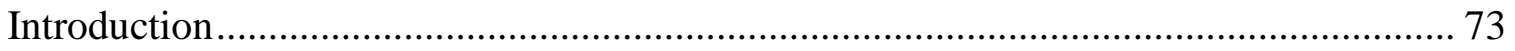

Toward a Model of Self-Efficacy Learning in Occupational Therapy .......................... 76

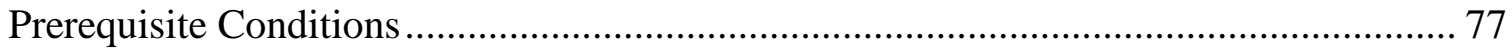

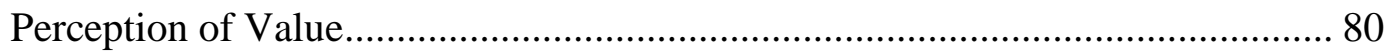

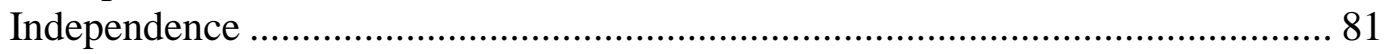

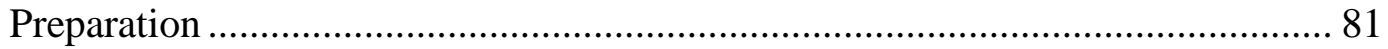

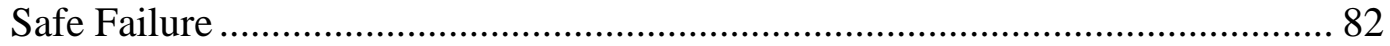

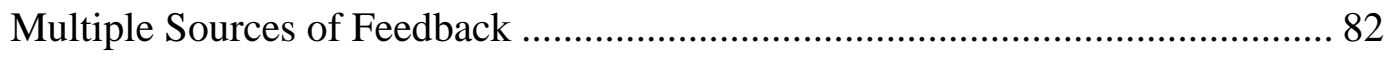

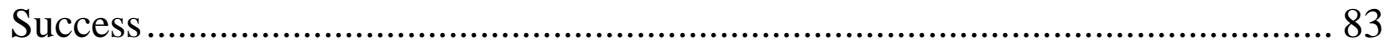

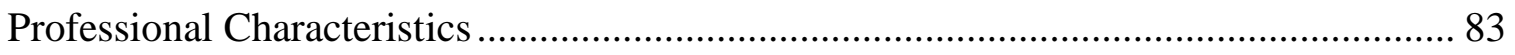

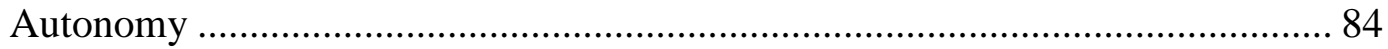

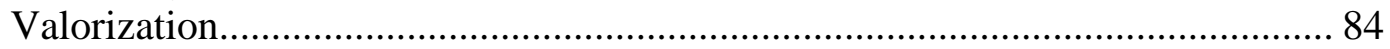

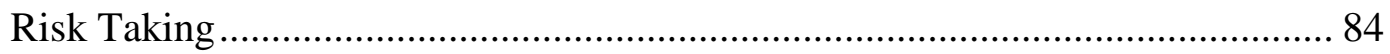

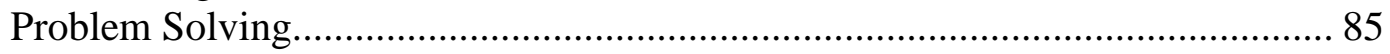

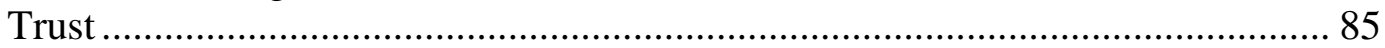

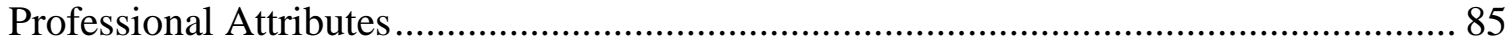

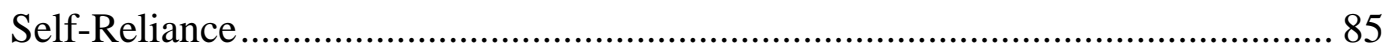

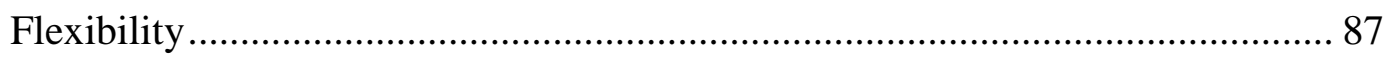

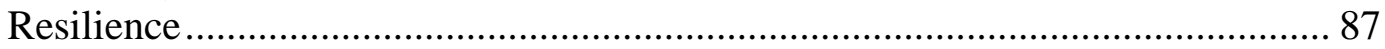

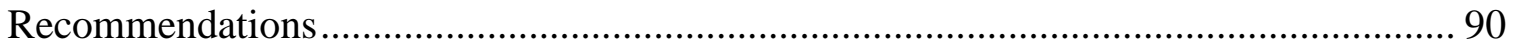

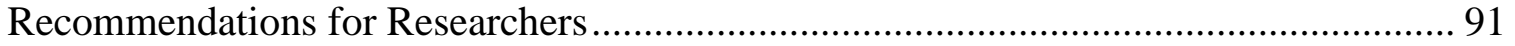

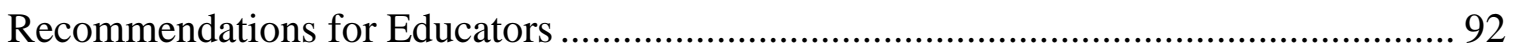

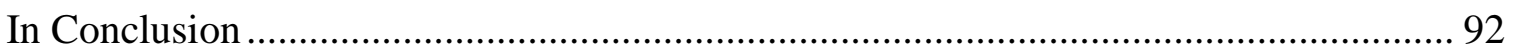

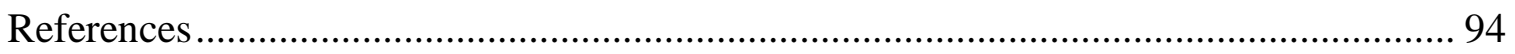

Appendix A: Participant Informed Consent ........................................................... 105

Appendix B: Internal Review Board Approval .......................................................... 109

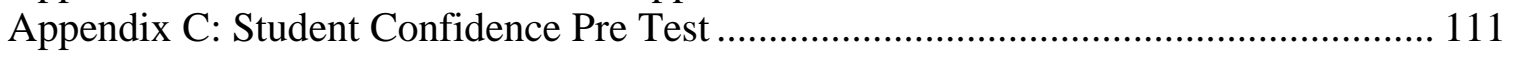

Appendix D: Student Confidence Post Test ............................................................. 116

Appendix E: Permission to Use Confidence Questionnaire ........................................ 121

Appendix F: Instructor Reflective Questions ........................................................ 123 


\section{List of Tables and Figures}

Table 1. Paired T-Test Results on Total Scores and Subscales ........................................ 4

Figure 1. Model of Self-Efficacy Education in OT ….................................................. 7

Table 2. Examples of Clinical Interactions among Attributes, Characteristics and

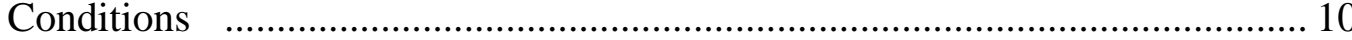




\section{CHAPTER 1}

\section{THE RESEARCH PROBLEM}

Students in the University of St. Augustine Occupational Therapy Program have reported feeling a lack of confidence prior to entering the Level II fieldwork portion of their education. Results of programmatic outcome measures such as focus groups, student satisfaction surveys and fieldwork course evaluations indicate students feel insecure about patient interactions, selecting appropriate interventions and documentation of service. Students have often requested more clinical experience prior to fieldwork to increase their feeling of confidence and self-efficacy in occupational therapy practice. Currently, occupational therapy students participate in a course titled OCT 5811 Mock Clinic in the occupational therapy curriculum at the University of St. Augustine. The course is offered as a part of their fifth term didactic curriculum just prior to leaving for a six-month fieldwork experience.

The course description follows:

“This course prepares students for their Fieldwork II experiences. It integrates occupational therapy theory and practice with clients in both traditional and nontraditional settings using information gained from all coursework. Using a mock clinic, the student will practice history taking and objective assessments with the client. From the information gathered in the subjective and objective evaluation, the student will develop problem lists, long-term and short-term goals, and implement a treatment plan with appropriate documentation for the setting" (USA Course Catalog, 2016, p. 155).

In an effort to meet course learning objectives as outlined in the course description, faculty have implemented service learning to provide experiential opportunities for students to practice skills and knowledge gained from course work. 
This study evaluated student participation in a community-based service learning experience offered in the Masters of Occupational Therapy (OT) Program at the University of St. Augustine for Health Sciences (USAHS) as a part of the mock clinic course, to identify how students' perceptions of their clinical reasoning abilities change after they participate in a service-learning experience. Previous research calls for an identification of the most salient characteristics of service learning that promote an increased perception of self-efficacy (Atler \& Gavin, 2010).

\section{Background of the Study}

Active learning has been proposed as one means of developing critical thinking skills essential to practice (Griffiths \& Ursick, 2003; Higgs \& Jones, 2000; Hooper \& Mitcham, 2004). Practice decisions require a synthesis of multiple information sources, including evidence, client information, and one's own experiences which requires strong critical thinking and clinical reasoning skills (Velde, Wittman, \& Vos, 2006; Peganoff, O’Brien, \& D’Amico, 2004).

Because transferring knowledge from the classroom to practice settings is difficult, educators have suggested a shift of instructional focus from content to the process of critical thinking (Torcivia \& Gupta, 2008; Velde et al., 2006). The focus on development of critical thinking skills and clinical reasoning requires instructors to facilitate students in a process of self-reflection. When students engage in reflection associated with active learning they become aware of their own assumptions and how assumptions may indirectly influence decision-making in practice (Torcivia \& Gupta, 2008). Active learning not only influences knowledge development but also improves the students perception of their ability to use this knowledge and in turn supports the development of clinical reasoning (Alderman, 2004; Schunk, 2004).

Service learning is one type of pedagogical methodology associated with active 
learning. Service-learning, defined as "a form of experiential education in which students engage in activities that address human and community needs together with structured opportunities intentionally designed to promote student learning and development" (Jacoby, 2003, p. 5), is used frequently in allied health education (Brown \& Wise, 2007; Gitlow \& Flecky, 2005; Narsavage, Lindell, Chen, Savrin, \& Duffy, 2002; Olivier, Oosthuizen, \& Casteleijn, 2007). Recent service-learning studies have examined the impact of this type of experiential learning on students' knowledge, skills, and confidence (Beck \& Barnes, 2007; Kelly \& Miller, 2008; Kramer et al., 2007; Portney \& Applebaum, 2006; Reising, Allen, \& Hall, 2006; Romani \& Holbert, 2007; Peganoff et al., 2004). These studies provide evidence that service learning can not only change students' knowledge of content related to practice, but also their confidence or comfort level in providing services (Denton, Esparza, Fike, Gonzalez, \& Lundquist, 2016).

Physical therapy and nursing students reported that they felt their competency related to assessment skills such as taking blood pressure and heart rates improved when they could participate in service learning activities. It was also reported that communication and patient intervention skills improved after participating in servicelearning activities. (Brown \& Wise, 2007; Portney \& Applebaum, 2006; Reising et al., 2006; Denton et al., 2016). Mary Law, states, "through service learning, students participate in school programs and gain a genuine context in which to deepen their learning about occupation, social justice and cultural diversity" (Law, 2010, p.15). Literature in education supports the use of service learning as an active learning method as a way of influencing students' beliefs or perceptions of abilities. Alderman (2004) states, "personal experiences, or completing tasks, are the most influential source of efficacy information because it is direct evidence of whether one can do whatever it takes to succeed" (p. 72). Higher self-efficacy has been demonstrated as associated with greater 
motivation, sustained efforts, and higher achievement (Alderman, 2004; Schunk, 2004).

Educational models support the use of active learning strategies for knowledge development. According to Kolb's learning theory "learning is the process whereby knowledge is created through the transformation of experience." (1984, p. 41). Kolb (1984) also describes a "cycle of learning" in which we experience, reflect, think, and act. According to this theory we reflect upon experiences, and those reflections are developed into concepts that can guide future action. It is the repeated testing of these concepts that create knowledge within new experiences. In Kolb's framework, learning is a continuous process. Learning is dynamic and not always comfortable and thrives on complexity. Learning is reliant upon the interaction with others and the surrounding environment (Schunk, 2004). These ideas are similar to a belief in occupational therapy because occupation emerges from the transactional relationship between person, occupation and environment. It is believed that we create knowledge through our interaction between the person and the environment, and knowledge is created through participation (Paavola, 2005).

Knowledge development in occupational therapy not only requires the learner to learn new skills and facts but also to be able to utilize this knowledge within complex clinical reasoning processes. Maureen Fleming (1991) describes the difference in clinical reasoning between the novice practitioner and the expert therapist. She describes that all therapists use multiple levels of reasoning when developing a plan for client care. She argues that developing this multilevel approach to reasoning is reliant upon a practitioner's experience. Experience assists the clinician in developing confidence in their problem solving and ability to use resources effectively (Fleming, 1991). With experience a practitioner develops confidence and improved self-efficacy. It is this 
improved self-efficacy that continues to influence the advancement of clinical reasoning skills.

Bandura defines self-efficacy as context based. Different than self-concept, which is defined as a perception of self, self-efficacy can be developed through multiple experiences of perceived success when one acts upon or within a certain context (1982). By adding service learning projects in the didactic portion of curricular delivery, we allow the student more exposure to opportunities for success prior to fieldwork or clinical practice. This additional exposure and feeling of success allows students to increase their sense of confidence with the problem solving expected in clinical reasoning, increasing their self-efficacy and clinical reasoning skills (Bandura, 1982).

\section{Statement of the Problem}

Occupational Therapy students are provided scenario-based learning and practical experiences within the curriculum to help develop clinical reasoning skills. However, even with these experiences our students lack confidence in their own abilities which drives their feeling of being "underprepared and anxious" about internship and clinical work. Service learning experiences within the curriculum provides an opportunity for OT students to apply academic learning in a real-world, underserved setting. This service learning experience is an ideal way to provide a structured, community-based opportunity for students to put their skills into practice.

Service learning experiences provide the opportunity for OT students to apply academic learning to a real population in a potentially underserved setting. Torcivia \& Gupta (2008) suggest that future evaluation of service learning activities should include the degree to which students' perceptions of their abilities change after participation in a service-learning experience. Some have also suggested that there be an attempt to identify the most salient characteristics of service learning experiences that promote this increased perception of self (Atler \& Gavin, 2010). As OT educators, we need to 
continue examining and providing evidence for service learning as one active learning approach that can prepare students to become stronger practitioners. If students are not only expected to be prepared to address the occupational needs of society, but also to be change agents to promote occupational justice, they will need to believe in their abilities to do so (Atler \& Gavin, 2010).

\section{Purpose of the Study}

Service learning is defined as "experiential education where students engage in activities that address human and community needs with structured opportunities intentionally designed to promote student learning and development" (Jacoby, 2003, p.5). This study evaluates student experiences in a community-based service learning project in the Masters of Occupational Therapy (OT) Program at the University of St. Augustine for Health Sciences (USAHS) to identify if students' perceptions of their abilities in applying the OT process change after participation in a service-learning experience. This study is an attempt to identify the most salient characteristics of service learning experiences that promote an increased perception of self within students.

\section{Significance of the Study}

Occupational therapy programs in universities can offer a solution to bridge the gap in access to service for clients and access to populations for practitioners. Literature has shown that using service learning as a teaching tool benefits both student learning and also offers access to resources to underserved populations and communities (Jacoby, 2003). Service learning in occupational therapy education has been identified as an important link between meeting the learning needs of the student, and meeting the occupational needs of the community (Beck \&Barnes, 2007).

Integrating service learning projects into course curriculum allows students to provide supervised services under the guidance of their instructors. The Accreditation Council for Occupational Therapy Education (ACOTE) requires that all faculty teaching 
in occupational therapy programs hold a current and active state license to practice (AOTA, 2016). Within the scope of this licensure, instructors can then supervise students in their provision of therapy services. Because service-learning projects can be provided as a part of coursework, these licensed practitioners are not reliant upon reimbursement from these services and because they are educationally focused they can provide these services pro bono to the community.

Therefore, these opportunities in service learning allow for additional services to be provided to the community to increase awareness of the role of occupational therapy to the leaders of the community, decreases financial restrictions for both the therapist and the consumer, and allows for increased community connection by providing a much needed service to people in need.

\section{Research Questions}

\section{Primary Research Question}

What are the salient characteristics of the service learning experience that contribute to the increase in perceived self-efficacy of occupational therapy students?

\section{Secondary Research Question}

Do service-learning experiences in occupational therapy education improve perceived self-efficacy in OT students?

\section{Research Methods}

\section{Research Design}

A mixed methods case study approach was used to evaluate student's perceptions of self-efficacy and identify characteristics of the service learning experience that contribute to improved perceived self-efficacy (Hoffman \&Silverberg, 2015).

\section{Study Sample}


Students from the University of St. Augustine San Marcos campus, Texas campus and St. Augustine campus, during their $5^{\text {th }}$ term Mock Clinic Course serve as the sample population. Students were asked to complete the pre and posttest of self efficacy using a questionnaire entitled OT Student Level of Confidence During Fieldwork Experience (Derdall, Olson, Janzen, \&Warren, 2002), and in addition will be asked to complete two reflection questions at the end of the five week course. Participation in the pre and post survey and reflection will not be a graded portion of the course requirements.

Faculty was asked to complete a survey to describe the experiential activities used at each campus to meet educational objectives of the course. The survey asks instructors to identify behavior changes in students that demonstrate change in self-efficacy related to clinical reasoning. Scores on the pre and posttest for each campus are compared to determine if experiential learning contributes to an increase in perceived self-confidence in students. Experiential learning experiences on each campus were compared to determine any significant differences in approaches that may contribute to development of student self efficacy. Through the process of comparative analysis, this study attempts to identify salient characteristics of participation in service learning that contribute to the development of perceived self-confidence in students.

\section{Data Collection Procedures}

Quantitative data regarding student self-efficacy was collected using a questionnaire entitled OT Student Level of Confidence During Fieldwork Experience (Derdall, et.al. 2002). This tool has been used previously to determine student selfefficacy as it relates to before and after clinical fieldwork rotations. This tool has a high level of reported internal reliability and significant construct validity and is a valid tool to indicate perceived confidence level in occupational therapy students (Derdall, et.al, 2002). This tool was given as a pre and posttest measure of student self-efficacy as it 
relates to participation in a service-learning project. This tool was given to all student participants at the beginning and the end of the five-week course.

Qualitative data was collected via a two-question prompt at the end of the fiveweek course. Reflection has been determined to be a valid means of evaluation of qualitative data in previously conducted studies related to service learning (Atler \& Gavin, 2010; Bazyk, Glorioso, Gordon, Haines, \& Percaciante, 2010; Flinn, Loos, Teaford, Clark, \& Szcucs 2009). Students were prompted to include aspects related to confidence and comfort and related to knowledge and skills within their reflections. To triangulate the data, course instructors were asked to complete a survey at the end of the course to identify their perceptions related to the growth of efficacy in the students. This faculty survey describes the experiential learning approaches and projects used to facilitate course learning objectives, a question related to whether or not they perceive student confidence in clinical reasoning to change because of participation in service learning, and a question related to identifying the aspects of their experiential learning project that contributed to change.

\section{Data Analysis}

The Statistical Package for Social Science (SPSS) was used to conduct descriptive statistics and a t-test to compare pre and post results of the OT student level of confidence questionnaire. Qualitative data collected via survey, student reflection and instructor survey was analyzed using content analysis and to identify themes related to the characteristics of the experience that influenced self-efficacy. Qualitative data were analyzed to determine any themes and correlations between data and to identify any salient characteristics of service learning that contribute to the outcomes.

\section{Summary}


This study evaluates the pedagogical methodology of experiential learning and how participation in experiential learning activities promotes the development of selfefficacy in the learner. Does participation in service learning, as one method of experiential learning, contribute significantly to the development of self-confidence and self-efficacy in students? Through participation in a service learning experience in occupational therapy curriculum it is expected there will be evidence of growth in confidence related to clinical reasoning skills for students. Hypothetically, this growth in confidence and professional self-efficacy can be attributed to the experiential nature of the learning in service learning. This study attempts to identify the specific characteristics of service learning experiences that contribute to the growth in self -confidence, professional self-efficacy and clinical reasoning.

It is believed these opportunities in service learning allow for additional services to be provided to the community to increase awareness of the role of occupational therapy to the leaders of the community, decreases financial restrictions for both the therapist and the consumer, and allows for increased community connection by providing a much needed service to people in need. Experiential learning activities, such as service learning are often reported as difficult to provide. Limitations such as faculty resources, uncertainty of specific learning outcomes, and logistical coordination with community sites limit utilization of this pedagogical approach. Occupational therapy education must continue to provide evidence for service learning as a valuable and often preferable learning approach that can prepare students to become practitioners if it is to remain a “signature pedagogy" for the profession (Shulman, 2005). 


\section{CHAPTER 2}

\section{LITERATURE REVIEW}

Service learning has been identified as an effective mode of active learning to influence students' beliefs regarding their abilities to apply knowledge to practice. Alderman (2004) states that personal experiences and successful task completion "are the most influential source of efficacy information because it is direct evidence of whether one can do whatever it takes to succeed" (p. 72). It has been demonstrated that using service learning promotes improved self-efficacy and is associated with increased motivation, perseverance, and achievement (Alderman, 2004; Schunk, 2003, 2004). Designing educational experiences in health science curriculum that promote the development of self-efficacy supports the development of clinical reasoning and practice skills (Alderman, 2004; Law, 2010; Schunk, 2003, 2004). Identifying ways of developing student self-efficacy within occupational therapy curriculum is essential to support development of effective clinical reasoning for occupational therapy students (Fleming, 1991; Coates \& Crist, 2004; Koenig, Johnson, Morano, \& Ducette, 2003). Although service learning is recognized as a successful pedagogical approach to support the development of self-efficacy, it is unclear from the literature what characteristics or aspects of service learning contribute to changes in confidence, knowledge and skill. Atler and Gavin, 2010 suggest that future studies should attempt to identify what aspects of service learning as a pedagogical method contribute to the development of selfefficacy in students. By identifying the salient characteristics of a service learning experience that contribute to improved self-efficacy, future service learning experiences can be more effectively designed to promote development of clinical reasoning in occupational therapy education.

Theoretical Foundation 
An evaluation of learning theories has been conducted to identify pedagogical methods that best support the development of student self-efficacy and clinical reasoning in occupational therapy education. Theoretically, self-efficacy and clinical reasoning are best supported by experiential or active learning methods. According to Kolb's learning theory "learning is the process whereby knowledge is created through the transformation of experience." (1984, p. 41). Kolb (1984) describes a "cycle of learning" that includes experience, reflection on that experience, thinking about the experience and how to change the approach, and future action based upon that new knowledge. Immediate experiences are reflected upon, and then are assimilated into knowledge to be used in future actions. (1984) In Kolb's framework, learning is a continuous and dynamic process that thrives on complexity. Knowledge is created through a shared experience. These ideas are similar to occupational therapy with the belief that occupation emerges from an interconnected relationship between the person, the task and the environment. Paavola (2005) confirmed Kolb's belief by stating that we create knowledge through our relationship with the environment, and through doing.

Adult learning theories have designed methods of evaluating adult cognitive development in stages that exceed the beyond the concrete operational stage originally proposed by Piaget (Eyler \& Giles, 1999). King (1992) identified that the average college students do not achieve critical thinking abilities necessary to be effective problem solvers. An evaluation of curriculum delivery in pharmacy education conducted by Zoreck, Sprague, \& Popovitch (2010) postulates that the traditional didactic delivery methods, such as lecture, promote "bulimic learning" that never allows the student to get beyond the first step of remembering, contributing to the students feeling unprepared for practice. They suggest that learner centered teaching and active learning strategies should be employed. Faculty should serve as facilitators to student learning and emphasis should be placed on teaching students how to learn (Zoreck, et.al Sprague, \& Popovitch, 2010). 
Experiential learning is an identified method of active learning strategies in occupational therapy education to facilitate development between theory, practical application and professional development (Cocker, 2010). Experiential learning is described by Cocker (2010) as "hands on experience in practical setting that can test the information learned in didactic coursework in an actual practice environment" (p. 281). Similar to the active learner centered strategies proposed by Zoreck et. al (2010), Cocker describes active learning methods with an emphasis on self-directed learning and encourages reflection within the learning experience to develop knowledge. It is proposed, "that experiential learning with an emphasis on active learning strategies involving clinical application may be the best method to improve critical thinking and clinical reasoning skills" (Cocker, 2010, p. 285). However, Cocker also suggests that further study is needed to determine what elements of experiential learning experiences enhance clinical reasoning and clinical thinking skills.

Experiential learning and active learning are proposed to develop the critical thinking skills essential to applying knowledge to practice in occupational therapy education (Griffiths \& Ursick, 2003; Higgs \& Jones, 2000; Hooper \& Mitcham, 2004). Law suggests that if we are open to new possibilities, experience can lead us towards new learning. In those situations, we develop knowledge (Law, 2010). Practice decisions require the therapist to synthesize information including evidence from the literature, specific client information with the experiences of the therapist (Velde, Wittman, \& Vos, 2006). This multilevel decision-making process requires strong clinical reasoning skills (Velde et al., 2006).

It has been asserted that effective pedagogical approaches must include the integration of experiential learning within the didactic structure of the academic classroom to enable students to develop clinical reasoning skills (Griffiths \& Ursick, 2003; Higgs \& Jones, 2000; Hooper \& Mitcham, 2004). Authors suggest that graduate 
level academic professional programs must respond to the dynamic and complex requirements of current clinical practice (Knecht- Sabres, Kovic, Wallingford, St. Amand, 2013); Griffiths \& Ursick, 2003; Higgs \& Jones, 2000; Hooper \& Mitcham, 2004). Because it has been acknowledged that transferring knowledge from a traditional academic setting to be utilized in the dynamic nature of practice is difficult, occupational therapy educators have suggested a change in instruction from a focus on delivering content to a focus on supporting the development of the process of critical thinking. Scholars have suggested that education include personal reflection, which would influence the development of actions plans. Outcomes should be evaluated related to the use of reflection and hands on approaches in the development of clinical reasoning skills (Griffiths \& Ursick, 2003; Higgs \& Jones, 2000; Hooper \& Mitcham, 2004; Torcivia \& Gupta, 2008; Velde et al., 2006).

Several studies provide evidence that service learning influences development of students' knowledge but it has also been found that students demonstrate an increase in confidence and comfort level in providing services (Brown \& Wise, 2007; Portney \& Applebaum, 2006; Reising et al., 2006). Physical therapy and nursing students reported that they felt improved competency related to assessment skills such as taking blood pressure and heart rates. These studies also reported that after participating in service learning activities, students experienced improvement in their patient communication and intervention skills (Brown \& Wise, 2007; Portney \& Applebaum, 2006; Reising et al., 2006).

By employing methods of experiential learning such as service learning in occupational therapy curriculum students may experience greater self-efficacy in their clinical reasoning skills. In order to fully support the development of clinical reasoning in occupational therapy students, curriculum must include opportunities to help students 
develop emotional intelligence and self-efficacy as a foundation to effective clinical decision-making and problem solving. Therefore, this study will utilize lessons learned related to experiential learning theory in occupational therapy curriculum specifically the use of service learning as an instructional method to support the development of clinical reasoning skills and the development of self-efficacy in students.

\section{Service Learning}

Service learning is defined as "experiential education where students engage in activities that address community needs with structured opportunities intentionally designed to promote student learning" (Jacoby, 2003, p.5). "We build knowledge when we engage in social transformation, when we challenge ideas. Fostering curiosity may lead to knowledge that no one could have imagined" (Paavola \& Akkarainen, 2005, p. $\mathrm{xxx}$ ). Service learning has been identified as a pedagogical method that benefits both student learning and also offers access to resources to underserved populations and communities (Jacoby, 2003). Eyler and Giles (1999) noted, "service learning is specifically designed to counter the isolation of learning from experience" (p. 256). Service learning as a pedagogical approach has been identified in supporting the development of students' clinical reasoning in health care education (Beck \& Barnes, 2007; Flinn, Loos, Teaford, Clark \& Szcucs, 2009). Studies have identified that service learning supports students' development of knowledge and skills in clinical reasoning (Bazyk, Glorioso, Gordon, Haines \&Percaciante, 2010; Beck \& Barnes, 2007; Kelly \& Miller, 2008; Kramer et al., 2007; Portney \& Applebaum, 2006; Reising, Allen, \& Hall, 2006; Reising et al., 2008; Romani \& Holbert, 2007).

Knecht- Sabres, Kovic, Wallingford, and St. Amand (2013) evaluated the integration of adult learning strategies into a course to enhance the student's skills and confidence with a variety of foundational skills. The benefit of the approach utilized in this study is that content is directly applied during situational learning opportunities 
similar to the "real context" providing students an opportunity to learn from their mistakes in a non threatening environment and prepare for the complex nature of clinical practice. Outcomes indicate an improvement in student's clinical reasoning, confidence and competence in their knowledge and skills when experiential learning methods are used (Knecht-Sabres, et. al, 2013).

Townsend and Whiteford (2005) propose that clinical reasoning in occupational therapy requires three "pillars" of knowledge. These three primary aspects include understanding occupational participation, developing client-centered approaches and advocating for occupational justice (2005). Practitioners help people to establish or return to occupational participation to facilitate health promotion through a unique understanding and identification of the individual's needs and desires, environmental affordances and limitation and personal capabilities and challenges. Occupational justice refers to the beliefs that guide clinical decision-making that promotes an individual's right to participate in occupations important for health and wellbeing. Occupational therapists believe that healthful participation in occupations is a basic human right for individuals (AOTA, 2015). However limitations in occupational therapy services, such as cost and availability of services, prevent occupational therapists from the ability to meet some of the occupational needs of the community.

Service Learning in occupational therapy education has been identified as an important link between meeting the learning needs of the student, and meeting the occupational needs of the community (Beck \& Barnes, 2007; Peganoff, O’Brien \&D’Amico, 2004). Beck and Barnes (2007) define this equality of addressing student learning needs and society's occupational needs as reciprocal service learning. Reciprocal service learning experiences provide the opportunity for occupational therapy students to apply academic knowledge in a safe environment while providing authentic service in an 
underserved setting. Service learning also offers a means to addressing the occupational needs of an underserved population frequently limited by access, financial restrictions and resources. Because service-learning projects can be provided as a part of coursework, these licensed practitioners are not reliant upon reimbursement from these services and because they are educationally focused they can provide these services pro bono to the community (Peganoff, O’Brien \&D’Amico, 2004). This allows services to be provided that are not financially restrictive to particular populations.

Langstraat and Bowden (2011) identified that the experiential and hands on nature of service learning has the potential to contribute to the improvement of a student's intellectual and emotional development. Active learning impacts the development of new knowledge, however, it also may influence self-perception of abilities. This increase in understanding of ability can contribute to development of improved professional selfefficacy (Alderman, 2004; Schunk, 2004). With an improved perception of professional self-efficacy, occupational therapy students will in turn develop a more effective approach to clinical reasoning. Service learning has been identified to increase student motivation and improve student attitudes toward education (Eyler \& Giles, 1999; Langstraat \& Bowden, 2011). However Langsraat and Bowden (2011) identified that most studies only implicitly address the emotional development associated with service learning pedagogies. Langstraat and Bowden (2011) proposed that the limitation of the literature to address emotional development is likely due to the association of emotions to that of a uniquely individual experience and one that is difficult to measure rather than a social experience reliant upon the interactions of others within a context. Emotional intelligence has been identified as a skill related to improved task performance and work performance (Lopes, Grewal, Kadis, Gall, \&Salovey, 2006; Carmeli, Josman, 2006; Caruso, 1999). In occupational therapy literature, a positive association has been made between emotional intelligence, self-efficacy and occupational therapy students 
performance on fieldwork (Andonian, 2013). Occupational therapy students should develop a deep understanding of themselves, and how their implicit biases may influence clinical decision-making. Engaging students in a reflection process associated with active learning can increase awareness of their implicit biases (Torcivia \& Gupta, 2008). For this study, emotional development related to self-efficacy is seen as reliant upon interaction with others within a specific context to influence development of clinical reasoning skills, and is an aspect of development that should be emphasized prior to the fieldwork experience.

\section{Clinical Reasoning}

Clinical reasoning has been identified as the skill that is most difficult to teach occupational therapy students (Facione, \&Facione, 2008; Mattingly, 1991). According to previous studies it is experience and confidence that ultimately facilitates the development of self-efficacy and clinical reasoning skills (Facione, \&Facione, 2008; Mattingly 1991, Fleming, 1991; Mattingly \& Fleming 1994). Clinical reasoning includes the therapist's understanding of personal and practice contexts. To facilitate the development of clinical reasoning, occupational therapy programs should address the emotional development required for this skill as an essential component of a personal context required for clinical reasoning (Facione, \&Facione, 2008). Self-efficacy has direct influence on developing clinical reasoning skills. As recommended in previous studies, this study will attempt to identify the salient characteristics in service learning approaches that support the development of self-efficacy in occupational therapy students.

It has been proposed that practice skills are strengthened by educational approaches that support the identification of personal beliefs and help students to develop an understanding of how entwined their knowledge is within their personal context (Schell \& Cervero, 1993; Schell, 2003). Clinical reasoning depends on the professional's 
ability to identify and use the best means for achieving a given end (Facione, \&Facione, 2008; Mattingly, 1991). To develop an ability to identify and implement the best means for a given situation, a therapist must have a deep understanding of practice procedures and guidelines, however, also interpersonal skills. The ability to use interpersonal skills as a therapeutic medium requires a deep understanding of self by the therapist. Much of the work on understanding clinical reasoning in health science disciplines relies on procedural methods for determining the diagnosis prognosis and treatment of diseases and medical conditions. Although occupational therapists work within the health care systems, the nature and goals of the practice of occupational therapy differ from the goals of other health care disciplines. Occupational therapy shares knowledge of the structure and function of the body and performance with other disciplines, however occupational therapy requires an understanding of the everyday rhythms of occupation. An occupational therapist must understand the complexities of human participation as it is influenced by limitation or disability including psychosocial influence, environmental limitations and affordances and the physical aspects of performance. Therefore the knowledge and reasoning strategies for occupational therapists would differ from that used in medicine and require a deeper understanding of emotional aspects of participation and a deeper understanding of self.

Concerns for individualizing treatment, facilitating independent functional performance and an emphasis on future participation lead the occupational therapist to emphasize different aspects of the person rather than the medical condition (Facione, $\&$ Facione, 2008; Fleming, 1991). This requires occupational therapy students to learn a different approach to clinical reasoning than other health professions. Schell (2003) defines clinical reasoning as the "process by which practitioners plan, direct and reflect on client care.”(p. 131) “Clinical reasoning treated as applied natural science is reasoning directed to the practical problems of prediction and control; it is a type of instrumental 
reasoning. From an instrumental perspective it is assumed that the professionals expertise is in her capacity to identify and put to use the best means for achieving given ends" (Mattingly, 1991, p. 980). Much of the work on clinical reasoning in medicine describes quantitative and deductive methods to determine diagnosis and treatment of medical conditions. Although occupational therapists work with people with medical diagnoses and disabilities, the goals of occupational therapy practice differ from the goals of physicians. The physician has a focus on alleviation or reduction of symptoms or illness related to disease. Conversely the occupational therapists role is to reduce the impact of the person's symptoms or illness on the person's life. Both professions are concerned with different aspects of function and health; however approach this with a different priority (Fleming, 1991).

Clinical reasoning in occupational therapy is much more inductive and qualitative in nature, with an attempt to help the client continue developing their life story. Therefore, therapists' knowledge interests and reasoning strategies will differ. Occupational therapists have increased concerns for individualizing treatment, facilitating or adapting functional performance and emphasizing participation within a new life view for the person. The occupational therapist will consider aspects of the person's life such as environment and participation more than the medical condition when designing interventions (Facione, \&Facione, 2008; Mattingly, 1991; Fleming, 1991).

Occupational therapist's clinical reasoning is based upon five domains of knowledge include in "understanding of the patient's motivations, commitments and tolerances, the environment in which the task is taking place, the therapist's knowledge of the physical and cognitive deficits, and the goals for the client" (Mattingly, 1991, p. 983). Evaluating all domains of occupational performance becomes integrated into the thought process of a practicing therapist. It becomes habituated so the therapist can pay attention to relevant cues during the interaction and unconsciously shift therapeutic 
interventions in response to what is observed and understood (Mattingly, 1991).

Mattingly proposed an alternate perspective of clinical reasoning in occupational therapy as "primarily directed not to a biological world of disease but to the human world of motives and values and beliefs. A human world of meaning” (Mattingly, 1991, p.983) In this perspective clinical reasoning then becomes applied phenomenology (Mattingly, 1991). Designing successful treatment process for a patient requires more than adapting the task to address motor and cognitive skills. Intervention involves creating a therapeutic experience that supports the client in dealing with deficit and dysfunction and can help them find meaning in life through participation and engagement. (Mattingly, 1991).

Maureen Fleming (1991) in her article about the therapist with the three-track mind describes the difference in clinical reasoning between the novice practitioner and the expert therapist. She describes that all therapists use multiple levels of reasoning when developing a plan for client care. She argues that developing this multilevel approach to reasoning is reliant upon a practitioner's experience. Experience assists the clinician in developing confidence in their problem solving and ability to use resources effectively (Facione, \&Facione, 2008; Fleming, 1991). Fleming suggests that therapists not only shift back and forth bust also keep track of each type of reasoning and the way the reasoning integrates into the treatment plan. All types of reasoning are often evident in the data collected during evaluation and assessment and in the interventions chosen. However they are rarely reviewed or brought to consciousness by the experienced therapist (Facione, \&Facione, 2008; Fleming, 1991).

Clinical reasoning in occupational therapy integrates multiple forms of reasoning including scientific reasoning, procedural reasoning, narrative reasoning, interactive reasoning, pragmatic reasoning, and ethical reasoning (Mattingly and Fleming 1994; Schell \&Cervero, 1993; Schell \&Schell, 2008; Torcivia, 2006). Scientific reasoning includes information about diagnoses or standard therapeutic procedures. This reasoning 
is based on understanding what evidence is available regarding an average person's illness experience, and using empirical evidence to choose the appropriate course of action. Procedural reasoning is based on existing practice or sequence of intervention rooted in the scientific reasoning principles noted in scientific reasoning. This type of reasoning is used when specific protocols are selected for intervention with a client based upon specific injury or illness (Fleming, 1991). For example, there is a specific protocol to follow while treating a person in recovery from a tendon repair to provide the appropriate follow up care to the surgical procedure. Narrative reasoning includes a consideration of the client's story of his or her illness and the unique impact it has on his or her life. Narrative reasoning is included in prioritizing interventions and areas of need for a client based upon how it fits into the individual's life story (Fleming 1991). Interactive reasoning informs decision making during the process of the therapeutic interaction. It is based upon the relationship between the therapist and the clients. This type of decision- making involves a deep understanding of how a client is responding or able to respond to treatment. This type of reasoning often operates parallel to the more rigid scientific and procedural strategies (Fleming, 1991). Pragmatic reasoning involves knowing affordances and limitations of settings. Therapists use this type of reasoning to identify the best way to use resources to meet the needs of the client. Pragmatic reasoning considers the influence of personal and practice affordances and limitations such as reimbursement regulations and equipment options (Fleming, 1991). Finally, ethical reasoning ensures that intervention is provided with the consideration of the principles and values of the profession and the therapists own belief system (Torcivia, 2006; Schell \& Cervero, 1993; Schell \&Schell, 2008; Mattingly \& Fleming, 1994).

The ability to simultaneously consider all forms of reasoning simultaneously and use that understanding to respond to changing conditions or predicting the possible client futures is known as conditional reasoning (Schell \&Schell, 2008). According to 
Mattingly and Fleming (1994) conditional reasoning is a multidimensional process involving complicated but not strictly logical forms of thinking. Conditional reasoning and the ability to simultaneously integrate multiple forms of information, requires therapists to be imaginative, curious and optimistic for future participation. According to the authors novice therapists reported that in their first year of practice they did not have the confidence nor the skills to interact with patients as individuals, and were limited in their ability to integrate all relevant information for optimal care (Mattingly and Fleming, 1994).

Schell \& Cervero (1993) state "clinical reasoning is a multifaceted process that includes not only scientific and narrative reasoning but also pragmatic reasoning directed to issues beyond those presented by the therapist- patient interaction"(p.609). Pragmatic reasoning according to Schell and Cervero (1993) "may parallel what Fleming described as conditional reasoning (1991) but its focus is much broader. It is not only concerned with the contextual issues affecting the patient now and in the future. It is also concerned with the personal context of the therapists and the culture of the practice environment" (p. 608). By simultaneously considering multiple aspects of performance, therapists can use clinical reasoning that is more effective for making daily decisions required in the complex nature of clinical practice.

Tornebohm (1991) proposed that each therapist represents a unique paradigm consisting of several parts. Each therapist uses their understanding of their personal view and ideas about occupational therapy, their personal abilities and skills in treating patients, and their life experience and personal beliefs. Reflectiveness is described as a relationship between the therapist's personal paradigm interacting with the paradigm of the client (Tornebohm, 1991). The therapists own motivation enters the clinical reasoning process when treatment decisions are based in part on what the therapist is willing and able to do within their own scope of training (Tornebohm, 1991). By suggesting the 
personal context of therapists as an important aspect of clinical reasoning this author suggests that improving clinical reasoning should include improving the therapists understanding of self (Tornebohm, 1991). Tornebohm postulates that personal life experiences of the therapist facilitate more effective clinical reasoning by offering opportunities for developing emotional intelligence (1991).

There is more to occupational therapy clinical reasoning than a practitioner's ability to use procedures and protocols effectively. Torcivia \& Gupta (2008) describe increased demands of current practice environments for occupational therapists. These demands include higher accountability and productivity standards, the ability of practitioners to use evidence to drive practice decisions and an increased demand of documentation to outline the effectiveness of interventions. Along with the pragmatic demands of health care, occupational therapists also face demands in the need to treat clients from diverse backgrounds, with the complex health, environmental and insurance coverage issues. Because of this, the authors suggest that practitioners develop an approach to treatment planning that integrates critical thinking within their clinical reasoning (Torcivia \&Gupta, 2008)

Torcivia \& Gupta (2008) claim there is a need for clinicians to develop metacognitive awareness. They believe therapists need to"think about their thinking" and self-awareness is "critical to ensure the best outcome for each client but also to enhance and invigorate the reasoning of practitioners (p. CE6)." Clinical reasoning requires critical thinking that is contextual and responsible. Critical thinking requires a practitioner to engage in frequent reflection to assess her reasoning (Torcivia \&Gupta, 2008).

In order to help a student occupational therapist to develop clinical reasoning skills the focus of education should change from a focus on content and competencies to a focus on developing thinking skills and judgment. The goal is to help students to 
become aware of their assumptions. Then support an understanding of how these assumptions connect to their clinical reasoning within the context of a situation to then create new knowledge and generate intervention plans (Torcivia \&Gupta, 2008).

In addition to the development of critical thinking skills, within the process of a student's self-reflection they must have an awareness of their own value structure and how that influences practice decisions. Fondiller, Rosage \&Neuhaus (1990) identified that the clinician comes to practice with a personal value system and set of beliefs that guides decisions made in treatment. As the outcomes of those decisions are experienced, and new information is received, not only will this change practice decisions but also it may have an influence on change within one's own value system. The contribution of a person's values on clinical reasoning must be acknowledged in order to comprehensively describe this process (Fondiller, Rosage \&Neuhaus, 1990). The clinician then identifies these changes to their personal values and beliefs through reflection (Fondiller, Rosage \&Neuhaus, 1990). Within this study values such as humanism and caring, patient independence and developing the profession's status were identified as influencing the clinical decisions of therapists (Fondiller, Rosage \&Neuhaus, 1990).

The ability of the occupational therapist to manage the many demands of treatment from the pragmatic and logistical to the emotional monitoring of the patient's feelings, managing the influence of ones own personal feelings, believes and values requires considerable emotional intelligence and self efficacy. Gardner (2011) suggested two kinds of interpersonal intelligence: the capacity to access ones own feelings and the ability to notice and understand differences of the feelings of other's. Gardner (2011) hypothesized that interpersonal intelligence is based on a well-developed sense of self and is associated with professional self-confidence.

Skills in emotional intelligence skills have been associated with good problem solving skills, leadership and integrity within work environments (George, 2000; Lopes, 
Grewal, Kadis, Fall, \& Salovey, 2006; Rosete \& Ciarrochi, 2008). George (2000)

identified how emotional intelligence can be used to influence the development and use of cognitive processes such as decision-making, prioritizing, and memory recall. Emotional intelligence can also be an element of developing self-efficacy within clinical practice (Coates \& Crist, 2004; Koenig, Johnson, Morano \&Ducette, 2003). Trainor (2008) identified that emotion and reason are intertwined in all decision-making processes, that emotions are socially experienced and can influence knowledge. These beliefs reflect Bandura's definition of constructing self-efficacy (1997). Skills in emotional intelligence can be seen as foundational to developing clinical decision-making skills during occupational therapy education (Andonian, 2013).

\section{Self-Efficacy}

Self-efficacy is "defined as an individual's belief in his or own competence" (Bandura, 1997). According to Bandura (1997), "perceived self-efficacy refers to beliefs in one's capabilities to organize and execute the courses of action required to produce given attainments" (p.3). Bandura identified self- efficacy as an influential factor for all human behavior. Bandura described self- efficacy as "one of the critical factors motivating people to engage in pursuing their goals" (p. 3).

Self-efficacy is grounded in the larger theoretical framework of social cognitive theory, which suggests that participation and achievement depends upon the interactions between ones own behavior, personal thoughts and beliefs and environmental conditions (Bandura, 1982). Learners develop self-efficacy through appraisal and feedback received related to performance. Personal experiences and the encouragement they receive from others and physiological responses provide feedback to inform and develop a perception of ability within a specific context of performance. Personal appraisals of performance behaviors influence beliefs of self-efficacy. Self-efficacy then influences choices related 
to tasks and participation, persistence or resilience within challenges and goals toward achievement (Bandura, 1997, Shunk \& Pajares, 1995). Students that display high selfefficacy for successful problem solving demonstrate greater task persistence, and greater ability to monitor their own performance (Bandura, 1997, Shunk 1995).

Continued exploration of the role of self-efficacy has led to an understanding that self-efficacy can be an effective predictor of students' motivation toward learning (Zimmerman, 2000). According to Bandura (1997), there are four recognized sources of self-efficacy. These sources include the student's participation and experience with “mastery experiences, vicarious experiences, verbal persuasion, physiological and affective states" (Bandura, 1997, p. 79).

Personal experiences that contribute to an individual experiencing mastery and achievement have the most influence on developing self-efficacy. It is believed that mastery experience provide the most influence on developing self efficacy since this type of experience provides the most authentic feedback of performance. Vicarious experiences are those opportunities where an individual will observe others succeed. For these experiences to be influential to development of self-efficacy the student must believe that they have comparable capabilities (Cone, 2009). Through the observations of someone else's success, a student may develop a sense of accomplishment because they perceive them selves capable of the same outcome.

Feedback related to verbal, or social, persuasion involves receiving meaningful feedback, whether positive or negative, from individuals that learners feel have deep knowledge or skill, such as instructors or mentors. Direct verbal feedback will allow students to gain insight into their performance and therefore contribute to their sense of capability within a task. Physiological and affective states refer to the experience and understanding of physical and emotional responses in reaction to stress, fear, and/or 
anxiety and the ability to overcome the feelings, thereby providing a sense of accomplishment and control over stressful situations (Bush, Powell \&Herzberg, 1993; Cone 2009). This sense of capability to meet task demands within a specific context is the foundation of self-efficacy.

Bandura describes self-efficacy as context based (Bandura, 1997). Different than self-concept, which is defined as a perception of self, self-efficacy can be developed through multiple experiences of perceived success when one acts upon or within a certain context (Bandura, 1982). Self-efficacy has been associated with behavior that contributes to achievement, motivation and performance in both academic (Brady- AMoon \& Furetes, 2011; Richardson, Abraham \& Bond, 2012) and work settings (Bandura, 1997; Vax, Schruer \& Sachs, 2012).

Student's self-efficacy has also been seen to support the development of clinical reasoning (Opacic, 2003; Utsey, 2006). In studies conducted with physician assistant interns, and physical therapy students it was identified that students with greater perceived self-efficacy performed better during their internships as rated by their clinical instructors (Opacic, 2003;Utsey, 2006). Atkison and Steward (1997) found that novice occupational therapy clinicians may be unaware of their own limitations, and it was later confirmed by Andonian (2013) that accurate self-appraisal is a critical factor in developing clinical competence and decision-making skills. Derdall, Olson, Janzen and Warren (2002) evaluated self-efficacy of students during fieldwork. Fieldwork experiences are typically provided at the end of didactic curriculum and require direct application of knowledge and skill in clinical practice. The authors found that the perceived self-efficacy of occupational therapy students increased from the start of fieldwork to when they were evaluated again at the end of fieldwork (Derdall et al, 2002). Therefore the clinical self-efficacy of occupational therapy students evolves with 
clinical experience (Derdall, et all 2002). Because fieldwork is the point at which students are expected to demonstrate appropriate, context based clinical reasoning skills, self-efficacy is an important construct to examine earlier in occupational therapy curriculum to improve the development of professional decision making skills required for occupational therapists.

Schunk (2003) proposes, "self efficacy can be enhanced through instruction methods that incorporate modeled strategies, progress feedback goal setting and self evaluations of progress" (p. 171). Providing the students with strategies that help them succeed can raise self-efficacy. Giving direct strategies that can be implemented immediately and monitored, they see the progress they are making and can increase selfefficacy (Schunk 2003). Implementing opportunities for development through experiencing "mastery experiences, vicarious experiences, verbal persuasion, physiological and affective states" earlier in occupational therapy curriculum will offer opportunities for development of student self-efficacy and, therefore, improve clinical decision making.

Cone (2009) proposes that offering students opportunities to observe more experienced clinicians demonstrate application of skills raises self-efficacy for learning and achievement. Watching others in the clinical decision-making and intervention process supports the development of a belief they can learn; students often believe they can then imitate the model and succeed (2009). Verbal feedback is also a source of selfefficacy information (Cone 2009). Performance feedback from instructors and mentors related to a person's attributions and ability contribute to self-efficacy. As students participate in clinical interactions the direct feedback received based upon the result of their action provides the information that then either reinforces their decision making, or helps to redirect choices. (Bush, Powell \&Herzberg, 1993; Cone, 2009).

Faculty play an important role in a student's development. Not only can positive 
feedback from faculty enhance occupational therapy student's professional self-efficacy, but interpersonal characteristics of faculty also have a great influence on developing a student's self efficacy. Bernadowski, P. \& Del Greco (2013), describe faculty as important role models because they demonstrate professional qualities and characteristics. They identified that student benefits from faculty with clinical experience, is well prepared, is stimulating and enthusiastic, shares feelings, give positive feedback in response to input, is supportive and encouraging and serves as a positive role model (Bernadowski, P. \& Del Greco, 2013).

Bandura's original assertion that developing self efficacy is supported through mastery experiences, vicarious experiences, verbal and persuasion and physical and affective states, perceived success or positive responses will reinforce student success. According to Bandura "Successes build a robust belief in one's personal efficacy." (1997, p.80). As Bandura (1997) stated, "People fear and tend to avoid threatening situations they believe exceed their coping skills, whereas they get involved in activities and behave assuredly when they judge themselves capable of handling situations that would otherwise be intimidating" (p.194). Bandura's theoretical framework of self-efficacy suggests that efficacy is more malleable in early learning. Thus experiences to promote the development of positive self-efficacy should be integrated early into curriculum. Swars, Smith, Smith, and Hart (2006) noted, “once ... efficacy beliefs are established, they are highly resistant to change" (p.2). The initial development of self-efficacy toward clinical practice has a potential impact on long-term clinical performance; therefore development of self-efficacy should be a focus of occupational therapy education.

\section{Summary}

Many previous studies have supported the use of active learning to promote the development of self-efficacy and clinical reasoning skills. Service learning has been 
identified as a successful pedagogical method within active learning. However, it is still unclear from the literature what specific aspects of service learning experience contribute to the development of self-efficacy and clinical reasoning for occupational therapy students.

Service learning is experiential education where "students engage in activities that address human and community needs, with structured opportunities intentionally designed to promote student learning and development" (Jacoby, 2003, p.5). Service learning as a pedagogical approach has been identified in supporting the development of student's clinical reasoning in health care education (Jacoby, 2003). Clinical reasoning in occupational therapy has been identified as multi dimensional (Mattingly \& Fleming, 1991). Effective clinical reasoning also include the therapist's understanding of scientific reasoning and practice contexts but also their personal values, beliefs and characteristics (Schell \& Cervero, 1993). It is proposed that practice will be strengthened by educational approaches that support therapists in the identification of their own theories and support a development of an understanding toward how embedded their knowledge is with their personal context, and how this impacts clinical decision making. (Schell \& Cervero, 1993). Developing self-efficacy within clinical practice is essential to integrate all aspects of clinical reasoning (Coates \& Crist, 2004; Fleming, 1991; Koenig, Johnson, Morano \& Ducette, 2003).

This study evaluates student participation in a community-based service learning experience in the Masters of Occupational Therapy (OT) Program at the University of St. Augustine for Health Sciences (USAHS). Student self-efficacy as it relates to clinical reasoning skills are assessed. Analysis of the data relates to the participation in experiential learning projects attempts to identify the most salient characteristics of these service-learning experiences that promote an increased perception of self-efficacy in students. By identifying the salient characteristics of a service learning experience that 
contribute to improved self-efficacy, future service learning experiences can be more effectively designed to promote student development in occupational therapy education. 


\section{CHAPTER 3}

\section{RESEARCH METHODOLOGY}

This study evaluates the experiences of students in a community-based service learning experience offered in the Masters of Occupational Therapy (OT) Program at the University of St. Augustine for Health Sciences (USAHS) as a part of the Mock Clinic course, to identify if students' perceptions of their clinical reasoning abilities change after they participate in a service-learning experience.

As discussed previously, educational literature clearly supports the premise that service learning can be an effective way of influencing students' beliefs or perceptions of their abilities. It has been demonstrated that using service learning promotes higher selfefficacy and is associated with greater motivation, sustained efforts, and higher achievements (Alderman, 2004; Schunk, 1995, 2004). Yet, previous research calls for an identification of the most salient characteristics of the experiences reported by the students engaged in service-learning that promote an increased perception of self efficacy (Atler \& Gavin, 2010).

Designing educational experiences in health science curriculum that promote the development of self-efficacy supports the development of clinical reasoning and practice skills (Alderman, 2004; Law, 2010; Schunk, 1993, 2004). Identifying ways of developing student self-efficacy within occupational therapy curriculum is essential to support development of effective clinical reasoning for occupational therapy students (Fleming, 1991;Coates\&Crist, 2004; Koenig, Johnson, Morano \&Ducette, 2003). Although service learning is recognized as a successful pedagogical approach to support the development of self-efficacy, it is unclear from the literature what characteristics or aspects of service learning contribute to changes in confidence, knowledge and skill. This study attempts to identify what aspects of service learning as a pedagogical method contribute to the development of self-efficacy in students. By identifying the salient characteristics of a 
service learning experience that contribute to improved self-efficacy, future service learning experiences can be more effectively designed to promote development of clinical reasoning in occupational therapy education.

The Master of Occupational Therapy Program at the University of St. Augustine uses experiential learning as a pedagogical approach during the Mock Clinic course in the $5^{\text {th }}$ term of the curriculum. Each of the three campuses uses a variety of methods of experiential learning in order to support the development of clinical reasoning skills in occupational therapy curriculum. Each campus offers students an opportunity to work with clients to conduct an assessment appropriate for the setting and client, develop an intervention plan and conduct intervention as well as develop a discharge plan for the client or population.

The master of occupational therapy program on the California campus uses service learning as a primary method of experiential learning. The Master of occupational therapy program on the California campus collaborates with Straight from the Heart (SFTH), a non-profit organization that provides education and support to foster families. As a part of a course, in the last term of the students' academic program, students conduct a needs assessment, and create and run three developmental play groups and parent resources for foster families associated with Straight from the Heart. Community participants within this network of foster families are invited to attend playgroups for children ages 0-3 for an hour and a half playgroup once a week that includes activities developed by occupational therapy students. Students select a theme such as under the sea, or superhero and offer age-appropriate activities within that theme to support gross motor, fine motor, tactile and cognitive development.

On the Florida campus students are assigned to a group to develop a treatment plan for a volunteer client. The individuals who are the clients have an existing condition and have previously received treatment. These individuals volunteer to participate in 
class and receive a student run assessment and treatment. This experience allows students the opportunity to work directly with a client and provide the experience of direct treatment. Students are able to observe other treatment sessions, and offer critique and suggestions to classmates. Students on the Florida campus also work with clients referred through the Council on Aging, providing health promotion strategies to the clients of local senior centers.

On the Texas campus students are also assigned to a group to develop a treatment plan for a volunteer client. The individuals who are the clients have an existing condition and have previously received treatment. These individuals volunteer to participate in class and receive a student run assessment and treatment. This experience allows students the opportunity to work directly with a client and provide the experience of direct treatment. Students are able to observe other treatment sessions, and offer critique and suggestions to classmates.

This service learning experience provided the opportunity for OT students to apply academic learning in a real world and underserved setting. This service learning experience provides a structured, community-based opportunity for students to put their skills into practice.

\section{Definitions of Variables}

\section{Service Learning}

Service learning is experiential education where students engage in activities that address human and community needs with structured opportunities intentionally designed to promote student learning and development (Jacoby, 2003). Beck and Barnes (2007) define this equality of addressing student learning needs and society's occupational needs as reciprocal service learning. Service learning experiences provide the opportunity for OT students to apply academic learning in a real-world, underserved setting. Service 
learning also offers a means to addressing the occupational needs of an underserved population frequently limited by access, financial restrictions and resources.

\section{Clinical Reasoning}

Schell (2003) defines clinical reasoning as the "process by which practitioners plan, direct and reflect on client care."(p131). It includes the ability to use multiple forms of reasoning simultaneously to inform practice decisions. Occupational therapist's clinical reasoning is based upon five domains of knowledge. These domains include understanding of the patient's motivations, commitments and tolerances, the environment in which the task is taking place, the therapist's knowledge of the physical and cognitive deficits, and the goals for the client (Mattingly, 1991).

\section{Self-Efficacy}

Self-efficacy can be simply defined as an individual's belief in his or own competence (Bandura, 1997). According to Bandura (1997), “perceived self-efficacy refers to beliefs in one's capabilities to organize and execute the courses of action required to produce given attainments" (p.3). Bandura describes self-efficacy as context based (Bandura, 1997). A student's perception of self confidence with clinical decisions can be directly associated with their perceived self efficacy for clinical decision making.

\section{Research Design}

This study employs a mixed methods case study to evaluate student's perceptions of self efficacy and identify characteristics of the service learning experience that contribute to improved perceived self-efficacy (Hoffman \&Silverberg, 2015). Quantitative procedures were used to collect pre and post test data regarding students perceived self confidence and self-efficacy related to clinical decision-making. A quasi-experimental design with pre and post measures was used to identify any change in confidence as a result of participation in experiential learning activities. All participants completed the 
pre and post questionnaire and results were evaluated using a paired t test to determine change.

Qualitative data was be collected via survey reflection at the time of post test data collection to identify the salient characteristics of the service learning experience that contribute to a perceived self-efficacy with clinical decision making. These responses were transcribed and data were analyzed using inductive content analysis for emergent themes.

\section{Appropriateness of Design}

In a review of literature regarding the methods of evaluation of service learning many methods were identified. McDonnell, Lloyd Jones and Reed (2000) noted that the design of any research study is influenced by theoretical perspectives but also must include pragmatic considerations. Therefore, with the intent of this study to identify the most salient characteristics of the service learning experience that contribute to an increase in perceived self efficacy in occupational therapy students a mixed methods case study has been chosen. The case study approach allows for the evaluation and description of student experience within a specific group of students. The intent of this study is to describe the characteristics of the service learning experience that contribute to the development of self-efficacy for clinical reasoning. This research question is based upon a hypothesis that students will experience an increase in perceived self-efficacy. Mixed methods has been defined as "the type of research in which a researcher or team of researchers combines elements of qualitative and quantitative research approaches (e.g., use of qualitative and quantitative viewpoints, data collection, analysis, inference techniques) for the broad purposes of breadth and depth of understanding and corroboration" (Johnson, Onwuegbuzie \&Turner, 2007, p.123). Mixed method case study approach has been selected to ensure accurate representation of the student experience of occupational therapy students at the University of St. Augustine. Quantitative methods 
are used in a pre-test posttest design to evaluate change in student self-efficacy.

Reflection through questionnaire was used to identify themes related to pedagogical characteristics that contribute to the change in self-efficacy.

\section{Research Questions}

\section{Primary Research Question}

What are the salient characteristics of the service learning experience that contribute to the increase in perceived self-efficacy of occupational therapy students?

\section{Secondary Research Question}

Do service-learning experiences in occupational therapy education improve perceived sel-efficacy in OT students?

\section{Participants}

A convenience sample of students combined from the University of St. Augustine California, Texas and Florida Campus during their $5^{\text {th }}$ term Mock Clinic Course serve as the sample for this study. 58 students were enrolled for this course across the three campuses and four Masters of Occupational Therapy Programs offered in Spring 2017, when data collection occurred. 58 students enrolled in the Spring 2017 semester for Mock Clinic course on all campuses were invited to voluntarily participate in the study. From the California Campus all 29 students enrolled participated in the study, 21 of the 22 students on the Florida campus participated, and 7 of the 9 students from the Texas campus volunteered to participate. The total sample included 56 students.

All student participants were asked to complete the pre and posttest of selfefficacy, and were asked to complete a reflection at the end of the five-week course. All course sections across all campuses utilize the same syllabus with the same learning objectives for the students. All course sections use experiential learning methods during this course, however not all campuses utilize service learning as the pedagogical method. 
Students were asked to complete the survey related to perceptions of self-efficacy both before and after their five-week course. Scores were compared. Instructors in the mock clinic course were asked to describe the pedagogical methods used to meet course learning objectives on their respective campuses and were asked to complete a two question follow up survey related to the perceptions of self-efficacy in their students. The information collected from participating faculty was used to triangulate the data received from the student participants.

\section{Informed Consent}

Approval was received by the Internal Review Board of the University of St. Augustine regarding procedures related to confidentiality of participants. Students were asked to voluntarily participate in the survey. Volunteer participants were provided an informed consent that will describe confidentiality procedures (Appendix A). Students were informed that participation in the surveys is voluntary and participation will not be included in the course grading procedures. The Internal Review Board of the University of St. Augustine has approved this study (Appendix B).

\section{Confidentiality}

Prior to completing the pre and posttest participants were assigned a random participant number by which data were associated and analyzed. The lists of associated participant numbers was kept separate from collected data, and remain in a locked cabinet. Participant numbers were only used to compare pre and post data to measure for change, and are not associated to any demographic information. Participation in the pre and post surveys was voluntary. Participation in the surveys was not be included in the course grading requirements.

\section{Instrumentation}

To identify the most appropriate way to measure a student's perceived selfefficacy, the literature offers multiple potential tools. Many studies evaluated clinical 
reflection and clinical reasoning. Most common tools used to gather this data were the Self Assessment of Clinical Reflection and Reasoning (SACRR) and the California Critical Thinking Skills Test (CCTST) (Cocker, 2010; Scaffa \&Wooster, 2004; Velde, et. al., 2006; Steinke \& Fitch, 2007). Although these tools have been used in published educational research to evaluate active learning on clinical reasoning skills of OT students and the CCTST has been widely used in health education research with good reliability and validity data, these evaluation tools do not specifically evaluate student self efficacy (Cocker, 2010; Scaffa \&Wooster, 2004; Velde, et. al., 2006; Steinke \& Fitch, 2007).

For this study student self-efficacy will be measured using the Student Confidence Questionnaire. The questionnaire was given prior to participation in the service learning project and then again following completion of the course. Scores were compared to evaluate change in student perceived self-efficacy. The Student Confidence Questionnaire, (Derdall, Olson, Janzen \&Warren, 2002), was developed to examine the level of occupational therapy student perceived self-efficacy during fieldwork. The measure uses a five-point Likert scale (Derdall et al., 2002). The course learning objectives for the Mock Clinic course are similar to the outcomes desired from fieldwork experiences. Because of this, the questions on the Student Confidence Questionnaire reflect the expected skills and knowledge of a student's learning within this course. (Appendix C)

Reflection and interview was used to gather data regarding a student's experience and perception of influential factors. Reflection has been identified as an essential component to achieving the goals of service learning (Eyler, 2002). Eyler noted that reflection is the one factor with considerable empirical research to show a positive impact on the educational outcomes of service learning (2002). Through the reflection process 
students are better able to integrate the experiences within the service-learning project with their own tacit knowledge (Eyler, 2002). Eyler (2002) proposes "it is through the reflection process that students are able to develop the knowledge skills and cognitive capacities necessary to deal effectively with the complex social issues that challenge citizens" (p. 517). These reflections were used as individual case studies and were compared for common themes that emerge relating to student experience (Appendix D).

\section{Validity/Reliability}

The Student Confidence Questionnaire demonstrates an internal reliability of Cronbach's alpha $=.96$. Construct validity was established with a sample of 29 students from one university in Alberta, Canada (Derdall et al., 2002). For the purposes of this study, this tool best evaluates the student's perception of self-efficacy in clinical application of course material given that it was developed specifically for occupational therapy and it has undergone validation testing. The author, Michele Derdall has given permissions to utilize this tool for this study to evaluate students self-efficacy related to participation in a service-learning project (Appendix E)

\section{Data Collection}

Quantitative data regarding student self-efficacy was collected using a questionnaire entitled OT Student Level of Confidence During Fieldwork Experience (Derdall, et.al, 2002). This tool has been used previously to determine student selfefficacy as it relates to before and after clinical fieldwork rotations. This tool has a high level of reported reliability and significant construct validity and is considered a validated tool to indicate perceived confidence level in occupational therapy students (Derdall, et.al, 2002). This tool was given as a pre and posttest measure of student self-efficacy as it relates to participation in service learning. This tool was given to all participants at the beginning and the end of the course. 
Qualitative data was collected via survey and reflective question prompt at the end of the five-week course. Reflection has been determined to be a valid means of evaluation of qualitative data in previously conducted studies related to service learning (Atler \& Gavin, 2010; Bayzk, 2010; Flinn 2009). Students were provided with two reflective question prompts at the completion of the service learning experience. These questions include:

1. How did the experiences in Mock Clinic impact your development as an OT student?

2. What aspects of this experience contributed to your learning or feelings of confidence?

In order to triangulate the qualitative data course instructors were asked to complete a two-question survey regarding their perceptions related to growth in efficacy in their students (Appendix F)

\section{Data Analysis}

SPSS was used to conduct a repeated measures t- test to compare pre and post test data and to identify if there was a significant change in confidence level after participation in the experiential learning activities. Qualitative data collected as a part of the survey, student reflection and faculty survey responses were analyzed using content analysis to determine qualitative themes as they emerge. Qualitative and quantitative data were then compared to determine any themes or correlations between data and to identify any salient characteristics of service learning that contribute to the outcomes. Three independent evaluators reviewed transcriptions to determine themes to ensure trustworthiness of results.

\section{Limitations/Delimitations}

A convenience sample was selected in order to more effectively control for sample size, however using convenience samples also impose limitations for 
generalization of results. The research design selected to evaluate the primary questions, although appropriate for this type of study, have some inherent limitations. Case study and qualitative research are limited in transferability and generalization of results to a larger population. Because this study was conducted at one institution, results can only represent student learning within the programs evaluated. Identified sample was limited to only those students who were enrolled in the identified course at the time of the study, for a more comprehensive evaluation, a larger sample of students enrolled in multiple sessions of this course could be used. This course is offered as a five-week course within the curriculum. This is a relatively short duration of time to measure change of a personal characteristic such as self-efficacy or self-confidence. Results may vary if given a greater duration and between pre and posttest. Also limitations can be attributed to the willingness, availability and agreeability of the faculty who were assigned to teach the course. Although all faculty who were teaching the course at the point of data collection were agreeable to helping with the student data collection, there was variability in participation on the faculty survey between campus, which may have an impact on the results. Although limitations have been identified, results from this study discussed in the next chapter offer contribution to the literature of experiential learning.

\section{Summary}

Although experiential learning methods such as service learning are recognized as a successful pedagogical approach to support the development of self-efficacy, it is unclear from the literature what characteristics or aspects of service learning contribute to changes in confidence, knowledge and skill. This study attempts to identify what aspects of service learning as a pedagogical method contribute to the development of selfefficacy in students. By identifying the salient characteristics of a service learning experience that contribute to improved self-efficacy, future service learning experiences 
can be more effectively designed to promote development of clinical reasoning in occupational therapy education. 


\section{CHAPTER 4}

\section{RESULTS}

A convenience sample of students recruited from the University of St. Augustine California, Texas and Florida Campus during their $5^{\text {th }}$ term Mock Clinic Course served as the sample for this study, and 58 students were enrolled in the course during the Spring 2017 semester when data were collected. All students were invited to participate (Appendix A). Of the 58 students enrolled 57 volunteered to participate and 56 students completed both the pre and post survey to be included in the sample. A mixed methods design was used to inform the research questions, using both quasi experimental and qualitative methodologies for data collection and analysis.

Quantitative data regarding student self-efficacy was collected using the $O T$ Student Level of Confidence During Fieldwork Experience Questionnaire (Derdall, et.al, 2002)(see Appendix B). As discussed previously, this tool was developed to determine student self-efficacy as it relates to before and after clinical fieldwork rotations, and it has yielded a high level of reported reliability and significant construct validity to indicate perceived confidence level in occupational therapy students (Derdall, et.al, 2002). This tool included 41 questions within seven subcategories of confidence characteristics. The seven subcategories of confidence assessed included communication, adaptability, innovation, risk taking, supervision, clinical practice and professional competence. Each subscale contained between 4-7 questions that included the preface " I am confident that I can:” followed by a behavioral statement reflective of the category. Participants rated their own efficacy on a Likert scale from 1 (strongly disagree) to 5 (strongly agree). All students were asked to complete the questionnaire at the beginning of the course as a pretest measure of self-confidence with clinical skills. At the end of the five-week course students were asked to complete this tool again as a post-test measure. Differences between the pretest and post-test scores were used as a measure of change in student self- 
confidence, with a positive score indicating growth, and a negative score indicating erosion of self-confidence.

\section{Findings}

\section{Statistical Analysis}

The Statistical Package for Social Sciences (SPSS) was used to calculate a paired samples T-Test for pre- and post-test scores on the Student Self Confidence questionnaire. Paired samples T-Test was conducted on the total score for participants to determine if there was a general change in overall confidence level. Similarly, a paired TTest was also conducted on each of the seven subscales with a confidence interval of 95\%. Results indicate a statistically significant positive change between pretest and posttest scores for all participants on all subscales and the total score, indicating a significant and consistent pattern of growth in student self-confidence. See Table 1 for a summary of results.

\section{Table 1}

Paired T-Test Results on Total Scores and Subscales

\begin{tabular}{|c|c|c|c|c|c|c|c|c|}
\hline \multicolumn{9}{|c|}{ Paired Differences } \\
\hline & & & & $\begin{array}{r}95 \% \mathrm{Co} \\
\text { Interva } \\
\text { Diffe }\end{array}$ & $\begin{array}{l}\text { fidence } \\
\text { of the } \\
\text { ence }\end{array}$ & & & \\
\hline & $\begin{array}{c}\text { Mean } \\
\text { Difference } \\
\text { Post - Pre }\end{array}$ & $\begin{array}{c}\text { Std. } \\
\text { Deviation }\end{array}$ & $\begin{array}{l}\text { Std. } \\
\text { Error } \\
\text { Mean }\end{array}$ & Upper & Lower & $\mathbf{t}$ & df & $\begin{array}{l}\text { Sig 2- } \\
\text { tailed }\end{array}$ \\
\hline Total & 66.15 & 51.27 & 6.85 & 79.88 & 52.42 & 9.66 & 55 & .000 \\
\hline $\begin{array}{l}\text { Subscale 1: } \\
\text { Communication }\end{array}$ & 4.73 & 3.84 & 0.51 & 5.76 & 3.70 & 9.22 & 55 & .000 \\
\hline $\begin{array}{l}\text { Subscale 2: } \\
\text { Adaptation }\end{array}$ & 2.36 & 2.27 & 0.30 & 2.96 & 1.75 & 7.78 & 55 & .000 \\
\hline $\begin{array}{l}\text { Subscale 3: } \\
\text { Innovation }\end{array}$ & 2.72 & 2.49 & 0.33 & 3.40 & 2.06 & 8.20 & 55 & .000 \\
\hline
\end{tabular}




\begin{tabular}{|l|r|r|r|r|r|r|r|r|}
\hline $\begin{array}{l}\text { Subscale 4: } \\
\text { Risk }\end{array}$ & 2.02 & 1.87 & 0.25 & 2.52 & 1.52 & 8.06 & 55 & .000 \\
\hline $\begin{array}{l}\text { Subscale 5: } \\
\text { Supervision }\end{array}$ & 1.70 & 2.62 & 0.35 & 2.40 & 0.99 & 4.84 & 55 & .000 \\
\hline $\begin{array}{l}\text { Subscale 6: } \\
\text { Practice }\end{array}$ & 2.50 & 2.77 & 0.37 & 3.24 & 1.76 & 6.75 & 55 & .000 \\
\hline $\begin{array}{l}\text { Subscale 7: } \\
\text { Professional } \\
\text { Competence }\end{array}$ & 6.55 & 4.78 & 0.64 & 7.83 & 5.27 & 10.26 & 55 & .000 \\
\hline
\end{tabular}

A paired samples t test was conducted to compare student confidence levels before and after participation in the service learning project. The analysis of total scores indicates an improvement in confidence after participation in the experiential learning activities offered on each campus. There was a significant difference in the total scores for pretest $(M=460, S D=64.4)$ and posttest $(M=526, S D=54.7)$ in student confidence levels $(\mathrm{t}(55)=-9.6, \mathrm{p}=.000)$.

Each subscale also indicated a statistically significant change $(\mathrm{p}<.001)$ with the largest mean differences observed in the subcategories of communication and professional competence. These results indicate a significant improvement among students in their perceived confidence with these skills.

The subscale of communication included items such as having confidence with client interaction, interacting with interdisciplinary team members, explaining the role of occupational therapy and confidence with documentation. Differences in scores within the communication subscale between pretest $(M=29.8, S D=4.65)$ and posttest $(M=34.5$, $\mathrm{SD}=3.65)$ indicated a significant difference $(\mathrm{t}(55)=-9.2, \mathrm{p}<.001)$.

The subscale of professional competence evaluated the student's confidence with practice skills. Practice skills include items such as analyzing activities, selection of assessments, establishing priorities for intervention and making recommendations for clients. Differences in scores in the professional competence subscale between pretest 
$(\mathrm{M}=31.5, \mathrm{SD}=5.3)$ and posttest $(\mathrm{M}=38.1, \mathrm{SD}=4.4)$ were significant $(\mathrm{t}(55)=-10.2$, $\mathrm{p}<.001)$.

The subscale of adaptability evaluated the student's ability to adjust to new clinical settings, handle challenges and the ability to alternate interventions as needed. . Differences in scores within the adaptability subscale between pretest $(M=18.7$, $\mathrm{SD}=2.68)$ and posttest $(\mathrm{M}=21.03, \mathrm{SD}=2.64)$ indicated a significant difference $(\mathrm{t}(55)=-$ $7.78, \mathrm{p}<.001)$

The subscale of innovation included the student's confidence with using problem solving techniques, making suggestions to supervisors and seeking out information to develop their own ideas. Differences in scores within the innovation subscale between pretest $(\mathrm{M}=18.8, \mathrm{SD}=2.76)$ and posttest $(\mathrm{M}=21.5, \mathrm{SD}=2.53)$ were significant $(\mathrm{t}(55)=-8.2$, $\mathrm{p}<.001)$

The subscale of risk taking assessed student confidence related to using techniques which students have observed, have practiced as well as techniques that may not be familiar. Within this category students were asked if they could learn from mistakes. Differences in scores within the risk taking subscale between pretest $(M=14.5$, $\mathrm{SD}=2.36)$ and posttest $(\mathrm{M}=16.6, \mathrm{SD}=1.78)$ indicated a significant difference $(\mathrm{t}(55)=-8.0$, $\mathrm{p}<.001)$

The subscale of supervision evaluated if a student was confident to receive feedback, seek feedback from supervisors and colleagues, delegate tasks and decide when to collaborate and when to be self directed. Differences in scores within the supervision subscale between pretest $(M=20.0, S D=3.11)$ and posttest $(M=21.7, S D=2.56)$ were significant $(\mathrm{t}(55)=-4.8, \mathrm{p}<.001)$.

The subscale of clinical practice identifies areas of confidence including supervising client programs, working on a team, handling autonomy and applying the role of OT in clinical practice. . Differences in scores within the clinical practice subscale 
between pretest $(M=19.3, S D=2.91)$ and posttest $(M=21.8, S D=2.52)$ were significant $(t$ $(55)=-6.7, \mathrm{p}<.001)$.

\section{Qualitative Analysis}

The questionnaire results collectively and individually led to the finding that there was significant growth in self-confidence during the period covered by the experiential learning activity. But these results alone do not shed light on what caused the change in self-confidence: whether in fact the change had anything to do with the experiential learning activities or were simply an artifact of maturation and growth in the program overall. Qualitative data collected during the post-instruction survey experience were evaluated to identify what aspects of the experiential learning activities might have contributed to the positive change in confidence observed among students during this period.

In order to address this concern, students were provided with two reflective question prompts at the completion of the service learning experience. These questions were provided in addition to the OT Student Level of Confidence During Fieldwork Experience Questionnaire (Derdall, et.al, 2002), and distributed by the faculty on each of the separate campuses to the participants as a part of the post test data collection procedures. These questions included: "How did the experiences in Mock Clinic impact your development as an OT student?"; and, "What aspects of this experience contributed to your learning or feelings of confidence?" This kind of reflection has been determined to be a valid means of evaluation of qualitative data in previously conducted studies related to service learning (Atler \& Gavin, 2010; Bazyk, 2010; Flinn 2009).

Inductive content analysis was conducted with the written student survey responses. Three independent evaluators reviewed the responses to identify emerging themes and patterns within the data. Three evaluators were used to ensure trustworthiness of results. The three reviewers included this investigator and two 
student research assistants who are also students within the occupational therapy program, however not students within the cohort assessed. Each evaluator independently reviewed transcripts of student responses to identify any common factors or ideas that emerged. The independent categories were then compared and only categories and codes that were agreed upon by all reviewers were included. Categories were determined on their ability to describe how the experience affected their development and with a focus on what activities or specific aspects of the learning experience contributed to their perception of this change. Transcript data was reviewed a second time by the primary investigator to organize the data according to the thematic codes and categories.

Through the analysis of the qualitative data, four aspects of experiential learning activities emerged as the primary contributors to an improved sense of self confidence: the perception of value, independence, multiple sources of feedback, and a safe environment to make mistakes. The course learning activities were described by respondents as being fast paced, and an opportunity for realistic application of didactic material. Many students reported that they enjoyed the opportunity to work with "real clients". The perception of the value and authenticity of the interaction increased the investment of engagement for the students. Students felt as though this was much better at helping them to apply their skills than working with "paper cases". Although the immediate feedback through the interaction with the volunteer clients is beneficial, more important is the belief that they are "actually helping someone" as opposed to "just learning" was a contributing factor to their engagement and feeling of growth. Participants acknowledged that the authenticity of the experience lent itself to the development of a greater sense of responsibility and self confidence. 
"Using intervention strategies on actual patients [rather] than

classmates, made it a great experience. Scary, but amazing. ")(CA

student)

"Hands on with real patients, it is very different from practicing

on each other."(TX student)

Some also noted that it was an increase in the sense of independence that offered an opportunity for risk taking, failure and success. Not having an instructor offer directive feedback at every moment allowed for the natural consequences of the choices to provide the feedback as to success or failure. This allowed students to feel as though they were wholly responsible for the outcome.

"Having to create a treatment plan and perform it without much assistance contributed to my learning and feelings of confidence." (FL student)

"Being autonomous and able to independently develop intervention plans and execute them to see if they worked" (TX student)

"Not knowing what to expect and learning to go with the flow and have a back up plan to the back up plan." (CA student)

Self-reliance is described as a person's ability to rely upon ones own efforts and abilities (Hacker, 2017). In this analysis, self reliance included student responses about autonomy and trust, which was consistent with the literature. Autonomy has been 
identified as an important aspect of clinical learning (Mazerolle \& Bowman, 2016). Mazerolle \& Bowman suggested that students be allotted opportunities to engage in self directed practice and make independent decisions to allow for the development of responsibility, competence, and confidence (Mazerolle \& Bowman, 2016). However to develop autonomy in decision making, our analysis suggests students must not only be allowed the opportunity for independence, but also develop a sense of trust to be able to initiate independent decision making.

"I am confident...knowing I don't know everything, but

I know how to figure it out." (FL student)

Participants reported that they developed an ability to trust their own clinical judgment and clinical instincts and that when they did, they could problem solve through unexpected situations. Students were provided the opportunity to develop trust in their training and in their instructors. Through these experiences they develop the belief that they had been provided with the skills and knowledge necessary to meet the clinical challenges independently. The opportunities for independent decision making provided through these experiences allowed the students to see how their own decisions affected client performance, without the faculty predicting and providing feedback beforehand. Students who were used to deferring to faculty or stronger peers were put in a position of having to decide on their own and receiving feedback only after the plan was enacted.

"The hands on work allowed me to apply my knowledge and prepared me for transition to fieldwork. Seeing real clients in a safe 
environment made me trust my instincts and facilitate growth. " (CA

student)

"Being hands on allowed me to learn and adjust and figure out

why certain things work or do not work on my own." (FL

student)

According to Torcivia and Gupta (2008), effective clinical reasoning requires the ability to flexibly respond to changing conditions and client needs, underscoring the need for flexibility in problem solving and decision making. Within this data flexibility describes a students' experiences with making initial preparations, but then relying on problem solving and the ability to adjust their thinking during sessions with clients. Along with the descriptions of the ability to rely on their own clinical reasoning and to be able to make effective decisions, participants described the understanding of the need to change their thinking in the moment. Participants identified the importance of effective preparation, expressed by the need to develop multiple plans for their client, but realized that to provide effective treatment, their plans needed to be fluid and able to change with the needs of the client. Examples include:

"I learned to address the real needs of the client- not necessarily what I thought would need addressing”, (CA student)

" Mock has prepared me to interact with clients, remain flexible and apply skills that I have learned" (FL student) 
"I learned that I needed to always adjust during treatment sessions"'(CA student)

Watching peers and provide feedback helped to develop an ability to develop new strategies and approaches. Observing others was reported as a tool for self-reflection of their own decision-making and interactions. It was also reported that observing a faculty mentor interact with "real clients" allowed students to connect their learning to clinical practice.

“ Observation of other students and having to give feedback to my peers helped me to think about what I was doing” (FL student)

"Seeing clients improve from week to week helped give me confidence that I am making good clinical decisions. "(CA student)

\author{
"Interacting with clients and being able to perform \\ assessment and interventions with feedback from peers, \\ clients and professors. " (CA student)
}

Feedback by instructors, clients and peers, offered an opportunity to grow and learn. The type of feedback was described as an important contributing factor to a feeling of growth. Feedback was immediate from clients related to the effectiveness of treatment selections. Peers offered direct and specific feedback related to intervention choices, and providing feedback to other students allowed the students an opportunity for self reflection. Instructors offered more feedback on approaches and behavioral attributes as opposed to specific interventions and methods selected. It was reported that faculty 
facilitated students to reflect to develop their own conclusions of what worked and what didn't. This self reflection allowed students to internalize the feedback and enabled them to make more direct changes for the next interaction with the volunteer clients. Feedback from volunteer clients was described as "forcing" students to not choose the memorized safe answer that would allow for a good grade, rather, truly understanding the critical thinking necessary to support their client's needs.

\author{
"Getting positive and constructive feedback to help me \\ improve my clinical reasoning and skills."(FL student) \\ "Receiving feedback also helped me to know what I was \\ doing right and what I needed to improve on." (TX \\ student)
}

To feel successful, students reported having to experience failure and reflect to develop an ability to identify their own limitations and then be allowed the supports to problem solve to enable a different approach and then they must experience success from that change of behavior. It is with this experience of self directed success after perceived failure that leads to the development of improved self efficacy and self confidence.

The most frequently reported characteristic reported by student respondents was that opportunities for "safe failure" contributed to their ability to develop the skills identified above as self-reliance and flexibility. Students perceived this environment to be a place where failure was allowed and they were offered the support to learn and grow from the mistakes. Respondents reported that they felt comfortable taking risks, and often felt as though they learned more and gained a greater confidence when they made a mistake and had to try again with the same client. Since grades for the course were not 
specifically focused on achieving a correct answer, students reported feeling as though they could take more risks in their approaches.

"Taught me to take changes to better my client, step outside my comfort zone and feel okay about making mistakes. (CA student)

"Recognize [the importance of] changing my plan when the session doesn't go as planned" (FL student)

"Having the professors near by but allowing us to do the treatment and make our own mistakes to learn from” (CA student)

Throughout the data a common theme of resilience emerged. Resilience is defined as a process of adaptation to adversity and stress and is a key component of well being (Bahadir-Yilmaz, \& Oz, 2015). Resilience has been described as a "quality necessary to succeed [for] medical and health science students" (Bahadir-Yilmaz, E. \& Oz, F., 2015, p. 386). Resilience is a useful skill not only when faced with extreme adversity, but also when dealing with more common stressful situations such as academic or professional transition points (Aswini \& Amrita, 2017). In this analysis the resilience category was used to describe opportunities for risk taking, making mistakes and having to recover and face those challenges repeatedly. Many respondents reported that learning was most impactful when they could learn from their mistakes. Students described the service learning experiences as a safe place to make mistakes, and they reported feeling as though they needed to develop trust and confidence to face a client again, even after mistakes were made.

"My confidence in my strength to endure through challenges grew immensely"'(TX student) 
"I learned the most when I made a mistake in treatment. No one was hurt and I was able to change the plan the next time." (CA student).

\begin{abstract}
"Provided affirmation that [making mistakes] is perfectly fine as long as you are trying to do your best"'(FL student)
\end{abstract}

Analysis of the qualitative data yielded three central themes related to how participation in experiential learning contributed to students' perceptions of increased self confidence: self-reliance; flexibility; and, resilience. When the educational experience considers the perception of value and authenticity of the experience, feedback from clients, faculty and peers opportunities for safe failure, and students experience self directed success professional self efficacy can be improved. It is through the opportunity of those environmental learning features students can independently plan and prepare, take risks, make mistakes, problem solve and trust their own capability, knowledge and training. Through this experience students can develop personal characteristics of self reliance, flexibility and resilience. Developing these characteristics contributes to an increase in a student's professional self efficacy, and to enhanced clinical reasoning.

"My confidence in my strength to endure through challenges grew immensely. Being able to practice assessments and interventions with real patients helped me to learn more about assessing and treating various deficits. I also feel more confident that I will be able to write a treatment plan that will be effective in meeting both my and my client's goals" (TX student) 
To triangulate the qualitative data, course instructors were asked to complete a two-question survey regarding their perceptions related to growth in efficacy in their students. Faculty were asked these questions: "How did the experiences in Mock Clinic impact the development of OT students"; and, "What aspects of this experience contributed to the students learning or feelings of self confidence?"

Faculty reported that they saw an increase in confidence within their students. They reported that many students encountered biases, and limitations in skills and knowledge they were not previously aware of through the direct interaction with the volunteer clients. Faculty reported that the experiential learning activities offered an opportunity to bridge the didactic learning and application of clinical reasoning and allowed students to develop skills in empathy and problem solving.

" Provided opportunities to grow, excel and explore in a safe environment." (TX Faculty)

"Students were able to begin to bridge the gap between didactic course work and clinical reasoning” (FL Faculty) "The experiences provided a safe learning environment for OT students. Continuous feedback and literal support of interventions created mentoring and guidance for student growth.” (TX Faculty)

"This experience lessened their anxiety overall about interacting with different types of people. Also they were more aware of their stigma against certain people once 
they met real clients and heard their experience. I feel that

the experience enhanced their ability to prove empathy with clients in the future." (CA Faculty)

The faculty described many of the same concepts as the student respondents as contributing to this increased sense of self efficacy. They reported an increase in perceived value of working with "real clients", a safe learning environment to apply didactic information, direct feedback from faculty and peers, and an ability to learn from mistakes as contributing factors to an increase of self confidence.

"Direct hands on experience with clients, going through the OT process from [evaluation, to treatment, to reevaluation and discharge ], direct collaboration with a faculty member, on going discussion about clinical reasoning, rationale and flow of treatment. (TX Faculty)

"The hands on experience in a safe learning environment allowed the students to put their plan into action and apply the concepts they have learned." (FL Faculty)

However faculty also reported that additional learning activities used to supplement the experiential learning activities were also beneficial. Faculty mentioned that developing a written plan of care, completing clinical competency activities out of textbooks and documentation activities, and even observing treatment by experienced clinicians contributed to the perception of increased self confidence in the students. 
"They completed clinical competence activities from the textbook, observe and critique their peers... participate in panel discussions about their clients and document the evaluation and treatment sessions." (TX Faculty)

"Utilizing the discussion board to write out their plan of care for the client. Students were required to review and discuss with the other groups about their plan" (TX Faculty)

"They were able to complete the written documentation on the evaluation results, but it was the communication of these reports with case managers that ... contribute to their ability to communicate and advocate for OT in the future." (CA Faculty)

"Observing as OT instructors modeled treatment techniques and communication with caregivers." (FL Faculty)

Data collected from student respondents, however, did not mention these activities as being beneficial. Although they may be important to the development of a skill and knowledge set needed by practitioners, the data did not suggest the value of these activities was understood by students or contributed directly to their sense of self efficacy with clinical reasoning. Although data did not indicate a perception of value, there is consideration as to the impact of these activities as necessary foundational 
components to a students knowledge development that contribute to the development of self confidence in application of knowledge.

\section{Summary of Results}

In conclusion, this chapter returns to the research questions that directed this investigation and summarizes the findings of the study and considers the findings for each.

\section{Research Question 1}

1) Do service-learning experiences in occupational therapy education improve perceived self-efficacy in OT students?

Results indicated significant growth in student confidence between pretest and posttest scores for all participants on total score and each subscale on the OT Student Level of Confidence During Fieldwork Experience (Derdall, et.al, 2002). These results suggest that participation in this service learning experience within the Mock Clinic Course of the Masters of occupational therapy program at the University of St. Augustine contributed to improved student scores of perceived self confidence. Qualitative data identified characteristics that contributed to a student's growth in self efficacy and attributed them to the service learning experience.

\section{Research Question 2}

2) What are the salient characteristics of the service learning experience that contribute to the increase in perceived self-efficacy of occupational therapy students?

Data indicated that it was the interaction of the prerequisite conditions of perceived value and authenticity of the experience, independence, preparation, multiple sources of specific feedback, safe failure and ultimate success that created the optimal opportunity for growth and improvement of self confidence. It is when these opportunities are presented that development of professional characteristics are facilitated. Students develop trust, valorization, problem solving, risk, and autonomous 
decision making. Through carefully facilitated experiences, and subsequent enhanced professional characteristic development the students then develop core professional attributes of self reliance, flexibility and resilience. Collectively, the development of these core professional attributes contributes to a greater sense of self efficacy and improved clinical reasoning for participants.

The concluding chapter will discuss the interaction, relevance and application of the above findings, and situate them in the literature. The results are used to construct an emerging model for developing self-efficacy in occupational therapy educational environments that emphasize service learning. 


\section{CHAPTER 5}

\section{CONCLUSIONS AND RECOMMENDATIONS}

\section{Introduction}

Shulman coined the term signature pedagogies meaning "the types of teaching that organize the fundamental ways in which future practitioners are educated for their new professions" (2005, p.52). Schaber, Marsh and Wilcox (2012) identified three signature pedagogies in occupational therapy education: active learning, relational learning and contextualized learning. According to Mitcham "these three signature pedagogies require effective instructional design and facilitation if they are to promote effective learning... and require a focus on occupation to uniquely support the needs of occupational therapy”(2014, p. 642). Mitcham proposed, “Our pedagogical focus needs to be learner centered in the same way our therapy practice is client centered" $(2014, \mathrm{p}$. 643). “Occupational therapy education requires pedagogies that promote opportunities for learners to explicitly see, listen and think about occupation through our professional filter" (2014, p. 642).

Service learning is an example of a pedagogical approach that embraces all three identified signature pedagogies in occupational therapy education; active, relational and contextualized learning. Because transferring knowledge from the classroom to practice settings is difficult, educators have suggested a shift of instructional focus from delivering content to developing critical thinking in occupational therapy education (Torcivia \& Gupta, 2008; Velde et al., 2006). Because of the dynamic and individual nature of occupational therapy, students must develop a strong sense of self-efficacy around their clinical problem solving and decision making. Using these types of experiential learning approaches in occupational therapy education provides the opportunities to facilitate the development of confidence to support clinical reasoning. 
This study was conducted as an attempt to identify what aspects of service learning as a pedagogical method contribute to the development of self-efficacy in occupational therapy students. By identifying the specific aspects of a service learning experience that contribute to improved professional self-efficacy in students, we can begin to develop a model for designing more effective service learning experiences that promote development of clinical reasoning in occupational therapy education.

As discussed in the previous chapter, results of pre and posttest scores indicated a statistically significant improvement in student's perceived self-confidence following an experiential learning course. Qualitative data revealed specific aspects of the experiential learning experience that contributed to an improved sense of self-confidence. Results of this study are used in this chapter to inform the development of a model of self-efficacy in occupational therapy. The nascent model can be used to develop experiential learning activities in occupational therapy education. This study identified that developing core professional attributes increased students' sense of professional self-efficacy and confidence with their clinical reasoning skills and therapeutic intervention skills.

The results also suggested that specific prerequisite conditions within the experiential learning experience were necessary for students to begin to develop specific professional characteristics. And through the development of these individual professional characteristics students grow in developing core professional attributes essential for effective clinical reasoning. As has been noted in the literature, advanced clinical reasoning in occupational therapy requires a true focus on the client within their specific context, at that specific moment with an integration of understanding of occupational performance (Mattingly, 1991). The personal feelings of the therapist must be suspended. To be able to reach this level of clinical reasoning, the therapist must develop professional attributes that are core to the occupational therapy profession. 
Mattingly has noted (1991) that this embodiment of professional attributes can be associated with the experienced clinician. Experiential learning, specifically service learning when it includes a focus on this type of character development, has the potential to support a student to achieve a sense of self-efficacy that will contribute to more effective clinical reasoning skills earlier in a therapist's career. More recently the literature has indicated a change in society that requires this shift in focus. In her 2014 Eleanor Clark Slagle lecture Maryanne Mitcham proclaimed

"Graduates must acquire more than new knowledge. For continued success graduates need to develop hard cognitive and pragmatic skills. Hard cognitive skills allow graduates to search for new information as it unfolds. But gleaning more information is not sufficient. They must create distinct criteria to assess the relevance of the retrieved information and develop judgment skills to consume only that information that is needed for their argument or solve a particular problem They need social and emotional intelligence especially in a profession called occupational therapy in which people environments and what they do come together in a carefully orchestrated pattern...For occupational therapy as profession to prepare new generations of practitioners it has to create education as product such that practitioners successfully navigate changing diverse and complex service delivery in health education and community systems" (pp. 637-638)

The development of a model that can be used to effectively design experiential learning activities to promote professional self-efficacy can improve a student's clinical reasoning skills. By doing so occupational therapy education can begin to support 
Mitcham's intention to create practitioners that can "successfully navigate changing diverse and complex service delivery in health education and community systems“ (2014, p.638).

\section{Toward a Model of Self-Efficacy Learning in Occupational Therapy}

The results of the study suggested a layered set of interrelationships among prerequisite conditions, professional characteristics, and ultimately, professional attributes which resulted in an increase in perceived self-efficacy. At the first level prerequisite conditions were necessary to create the optimal opportunity for growth and improvement of self-confidence. These prerequisite conditions include perceived value and authenticity of the experience, independence, preparation, multiple sources of specific feedback, safe failure and success. When these prerequisite conditions are in

place the development of professional characteristics are facilitated. Students begin to exhibit trust, valorization, problem solving, risk, and autonomous decision making. Through carefully curated and supported experiences, and the subsequent enhanced professional characteristic development, students begin to manifest core professional attributes of self-reliance, flexibility and resilience. Collectively, developing these core professional attributes contributes to a greater sense of self-efficacy and improved clinical reasoning for participants. It is the interaction of these categories of elements that constitute the beginning components of an emerging model for experiential learning to be used in occupational therapy education. By using this model to support the development of learning experiences, educators can attend to the development of core professional attributes that contribute to effective clinical reasoning (see Figure 1). 
Figure 1. Model of Self-Efficacy Education in OT

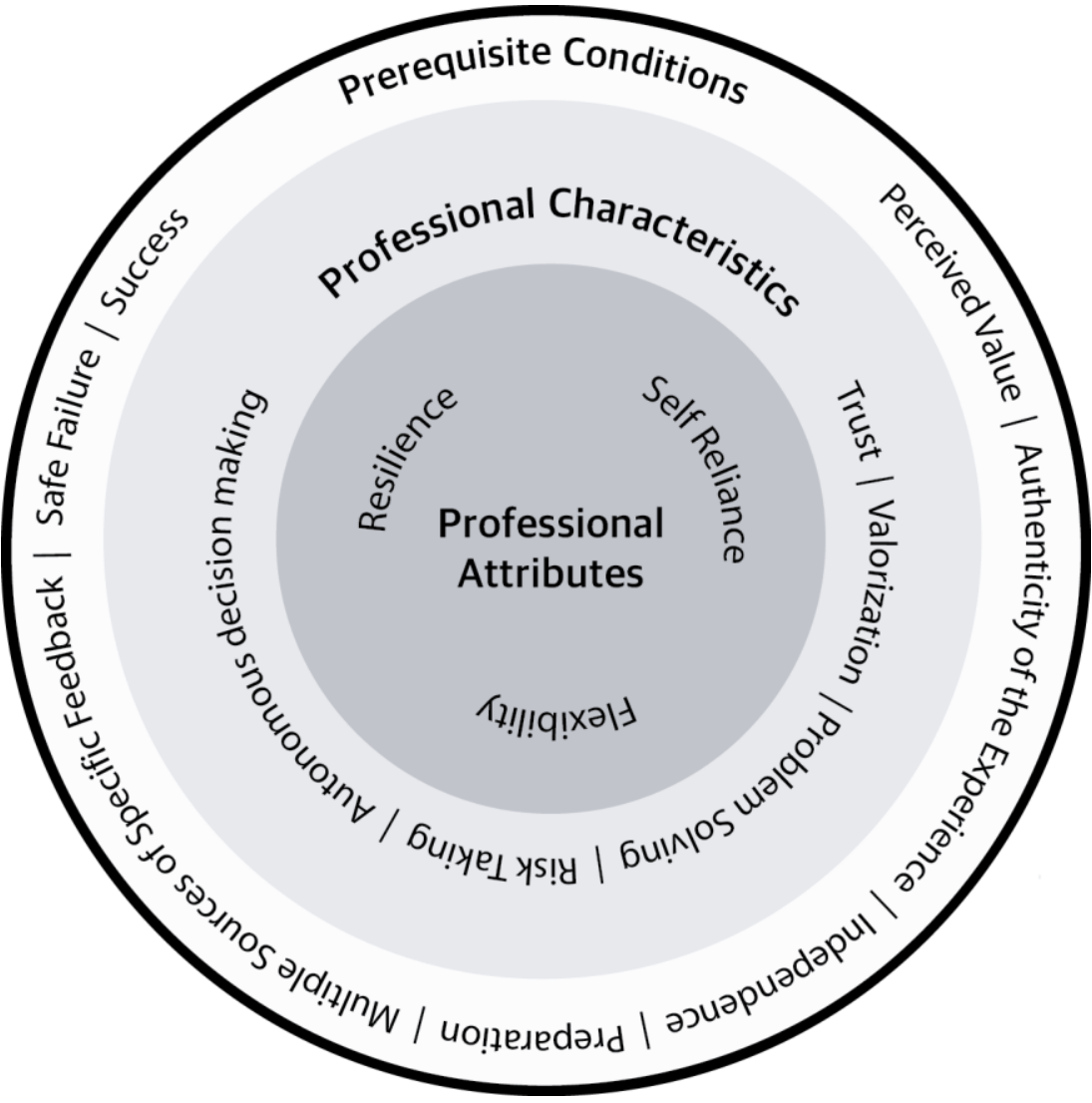

Each of the rings describes separate aspects of an experiential learning activity.

Although it is illustrated as concentric circles it can be thought of as layers of learning.

These layers are interdependent and relate to the central objective of developing professional attributes that contribute to a person's professional self-efficacy and effective clinical reasoning.

This is not however a static or linear model, nor are the components necessarily of equal importance. Each of the separate parts will shift and interact in different ways at different points of the experiential learning experience, resulting in different constellations of relationships in particular circumstances. To elaborate these conclusions, the next section of this chapter will consider each ring and element of the model. After elaborating on each of the separate elements the interaction will be discussed 
Prerequisite conditions describe those elements provided to students to allow for and facilitate the development of the professional characteristics and core professional attributes that lead to a strong sense of professional self-efficacy and improved clinical reasoning skills. These prerequisite conditions result from the setup of the pedagogical experiences, experiential learning opportunity, and although not mentioned in the student data, the interaction of the faculty. Together these elements promoted learning activities and scaffolding of curricular development.

This ring represents the foundational elements of the educational experience. From the data collected from the students these opportunities include perceived value, independence, safe failure, multiple sources of feedback and success. Elements drawn from the faculty data such as preparatory activities, although not mentioned by students as essential components to their development, may make a subtle but powerful contribution to the foundation needed to build the skills and characteristics that in turn promote self-efficacy. Perhaps those elements identified by faculty contribute to the student's trust in their knowledge and training. Perhaps those elements provide the scaffolding for the learning that is necessary for a student to be "ready" to be given independence. Because this experience is offered to students at the end of their curriculum to synthesize their learning, this likely helps a student to recognize familiar elements, feel connected to their previous learning and supported by faculty to engage in the environmental opportunities available within the service learning activities. Future research should evaluate to what extent these supportive learning activities contribute to a student's development of self-efficacy and clinical reasoning.

This also may include other elements in the environment not mentioned in this study, such as faculty personality, teaching methods and approaches, and delivery. What influence does faculty personality, demeanor, and approach to teaching have on experiential learning activities? This study provides no data, only speculation, based on 
the compelling argument that teaching — and therefore the teacher-has a profound influence on student growth. Teachers act, sometimes in the shadows, as a catalyst for change in students, and nudging them carefully and persistently toward independence.

Some students may notice these subtle actions, but most probably do not. Without the teacher's careful nurturing of their independence, they would not discover the elements they identify. These hidden prerequisite conditions are foundational to the development of the conditions identified and recognized by students in this study. Because these aspects are completely reliant upon the faculty and structure of the program, they can be more apparent to faculty while going unnoticed by students. Faculty have much more experience, and comparative knowledge to understand the importance of some of these activities, and because they have often created and delivered them they have a much deeper personal investment in this type of prerequisite conditions. These can often go unseen by students, and undervalued by students who do not have comparative experience, or personal investment in those specifics.

It is because of this variance in perspective I believe there was some variation between faculty and student responses in the data. Further investigation is needed to evaluate if this is in fact the case. Faculty reported that they saw an increase in confidence within their students. They reported that many students encountered biases, and limitations in skills and knowledge they were not previously aware of through the direct interaction with the volunteer clients. Faculty reported that the experiential learning activities offered an opportunity to bridge the didactic learning and application of clinical reasoning and allowed students to develop skills in empathy and problem solving.

The faculty described many of the same concepts as the student respondents as contributing to this increased sense of self-efficacy. They reported an increase in perceived value of working with "real clients", a safe learning environment to apply didactic information, direct feedback from faculty and peers, and an ability to learn from 
mistakes as contributing factors to an increase of self-confidence. However faculty also reported additional learning activities that were used to supplement the experiential learning activities as being beneficial. Faculty mentioned, developing a written plan of care, completing clinical competency activities out of textbooks and documentation activities as contributing to the perception of increased self confidence in the students. Data collected from student respondents however did not mention these activities as being beneficial. Although they may be important to the development of a skill and knowledge set needed by practitioners, the data are not clear whether these activities contributed to student's sense of self-efficacy with clinical reasoning.

These hidden elements are seductive when we evaluate the result of the student data and the aspects that emerged as necessary prerequisite conditions. Perhaps because these students were at the end point of their curriculum, although it was not overt in their responses, the hidden elements identify the aspects of a curriculum that prepare the student to be ready for just those conditions. A student would not be prepared to perceive value, know how to prepare effectively, be ready to have some level of independence with treatments, or even have a reference for the difference between success and failure within a therapeutic process, or benefit from feedback without the diligent preparation by course work and faculty mentors. However the focus of this research was on student perception, so this is merely a speculation about the future development of this emerging model. Additional research should be conducted to more specifically identify the aspects of preparation that are essential prerequisite conditions for developing personal professional characteristic and core professional attributes of an occupational therapist.

\section{Perception of Value}


The perception of the value of the interaction and learning experience increased

for the students. Students felt as though interacting with community volunteers and clients was much better at helping them to apply their skills than working with "paper cases". Although the immediate feedback through the interaction with the volunteer clients is beneficial, more important was the belief that they are "actually helping someone" as opposed to "just learning" was a contributing factor to their engagement and feeling of growth. Fredholm (2015) mentioned the need for authenticity as a prerequisite for development in clinical education. It was noted that situations needed to be real to have importance and to make a strong impact on students learning by creating feelings of relevance and meaning. "Relevance and meaning became apparent when actions and decisions had consequential impact on the patients' wellbeing and life situations" (2015, p.24). It is the opinion of this researcher that mentors create the value through the embodiment of passion.

\section{Independence}

The sense of independence also offered an opportunity for risk taking, failure and success for many students. Not having an instructor offer directive feedback at every opportunity allowed for the natural consequences of the choices to provide the feedback as to success or failure. This allowed students to feel as though they were wholly responsible for the outcome, good or bad.

\section{Preparation}

Preparation is the planning necessary to start to become ready for treatment. Students often have a false sense of confidence that their one idea or plan will be effective, then when it does not go as it did in their mind, or take as long as planned, or 
take too long, there is a difficulty in knowing what to do next. This type of preparation allows students to internalize the need to have not just one linear plan for a treatment session, but to plan differently and more effectively. Students learn to have multiple plans, with multiple variations, and plan for unexpected situations.

\section{Safe Failure}

The most frequently reported characteristic reported by student respondents was that opportunities for "safe failure" contributed to their ability to develop the skills identified above as self-reliance, flexibility and resilience. Students perceived this environment to be a place where failure was allowed and they were offered the support to learn and grow from the mistakes. Respondents reported that they felt comfortable taking risks, and often felt as though they learned more and gained a greater confidence when they in fact made a mistake and had to try again with the same client. Since grades for the course were not specifically focused on achieving a correct answer, students reported feeling as though they could take more risks in their approaches.

\section{Multiple Sources of Feedback}

Feedback by instructors, clients and peers, offered an opportunity to grow and learn. Feedback was immediate, direct and specific. The type of feedback however was described as an important contributing factor to a feeling of growth. Instructors offered more feedback on approaches and behavioral attributes as opposed to specific interventions and methods selected. It was reported that faculty facilitated students to reflect to develop their own conclusions of what worked and what didn't. This selfreflection allowed students to internalize the feedback and enabled them to make more direct changes for the next interaction with the volunteer clients. Feedback from 
volunteer clients was described as "forcing" students to not choose the memorized safe answer that would allow for a good grade, rather truly understanding the critical thinking necessary to support their client's needs.

Being able to watch peers and provide feedback helped to develop an ability to develop new strategies and approaches. Observing others was reported as a tool for selfreflection of their own decision-making and interactions. It was also reported that being able to observe a faculty mentor interact with "real clients" allowed students the opportunity to connect their learning to clinical practice.

\section{Success}

In order to feel successful, students reported having to experience failure. The opportunity to then reflect on that failure to develop an ability to identify their own limitations supported their problem solving. The ability to then develop and use a different approach, and experience success as a result of that change of behavior is most impactful for the student's development. It is this experience of self-directed success after perceived failure that leads to the development of improved self-efficacy and selfconfidence.

\section{Professional Characteristics}

Professional Characteristics are the characteristics that develop as a result of the prerequisite conditions. Professional characteristics emerge through an internalization of the personal experiences that occur when specific opportunities are provided. Students begin to personalize and embody those professional skills essential to occupational therapy practice. It is this personalization that enables the development of professional characteristics. Characteristics within this definition can be used to describe the 
individual qualities that each student develops as a direct relationship to those

prerequisite conditions. These qualities are individual, personalized and become an inherent part of the student's personality. It is these personal characteristics that then lead to the development of professional attributes associated with the profession of occupational therapy. These professional characteristics include autonomy, valorization, risk taking, problem solving and trust.

\section{Autonomy}

Autonomy occurs when independence is given to the students, and a faculty allows a student to develop the plan and enact the plan without facilitation. The student must be able to act autonomously to make the decisions necessary for effective treatment planning and follow through.

\section{Valorization}

Service learning can establish an opportunity for a perception of value, through the ability to provide service when service is needed. However it must be the internalization of that value or the valorization that occurs that will allow the student to personalize the value of the opportunity in association with their own value structure. When a student internalizes the value of an opportunity, the outcomes have a more personalized impact.

\section{Risk Taking}

When given opportunities for independence within a value structure, and a safety net is available, students can develop skills of risk taking. They will develop the abilitiy to try methods and activities that may not work, and be willing to do so because the 
perceived risk is less. However with that will be able to see greater benefit of risk taking to become much more self-reliant and resilient with the impact or the result of their decisions.

\section{Problem Solving}

Problem solving in authentic settings implies a more independent process. Students will not have instructors directing each decision made and students are not relying on faculty for reinforcement or approval. When challenges arise, the student must learn skills on how to evaluate effectiveness and develop alternatives as needed. It is through this opportunity that the need to rely on their own problem solving skills can develop.

\section{Trust}

In order to successfully take risks, and act autonomously, the student must have developed a sense of trust. This level of trust includes various facets such as trust in the process, trust in their faculty mentors and trust in their own knowledge base.

\section{Professional Attributes}

Professional Attributes are defined in this study as core qualities that are part of the profession as a whole. These qualities can be attributed to all occupational therapists and are necessary to be an effective practitioner. Therefore it is argued that educational programs should focus on developing these core attributes among their students to ensure the growth and support of the profession. These core attributes include self-reliance, flexibility and resilience.

\section{Self-Reliance}


Self-reliance is described as a person's ability to rely upon one's own efforts and abilities (Merriam-Webster, 2017). For the purposes of this study, self-reliance was a cluster of questions that the students were presented which included responses related to autonomy and self-trust. Autonomy has been identified as an important aspect of clinical learning (Mazerolle \& Bowman, 2016). It has been suggested that students should be allotted opportunities to engage in self-directed practice and make independent decisions to allow for the development of responsibility competence and confidence (Mazerolle \& Bowman, 2016). However to develop autonomy in decision making, students must not only be allowed the opportunity for independence, but also develop a sense of self trust to be able to initiate independent decision making.

Respondents reported that they developed an ability to trust their own clinical judgment and clinical instincts and that when they did, they could problem solve through unexpected situations. The opportunities for independent decision making provided through these experiences allowed the students to see how their own decisions impact client performance, without the faculty predicting and providing feedback beforehand. Students who were used to deferring to faculty or stronger students were put in a position of having to decide on their own and receiving feedback only after the plan was enacted.

Educational literature frequently reports on autonomy in learning (Fredholm, 2015; Perrin, 2014), and health science literature describes the development of autonomy with skill and practice. Self-directed learning and autonomy in learning have been connected to factors such as motivation, choice and the ability to identify learning needs and evaluate learning outcomes (Fredholm, 2015). Perrin (2014) identified learner autonomy as an "important aspect of experiential learning that contributes to student motivation and engagement" (p.5). Embedded within autonomy is an emphasis on the importance for the student to identify and solve problems rather than relying on a teacher 
or supervisor. This approach allows students to apply knowledge and become selfdirected as opposed to reactive in the outcomes. Autonomous/ supportive learning environments have been associated with deeper engagement in learning activities and better conceptual learning. Service learning allows for this type of supportive autonomy in application and exploration of course concepts.

\section{Flexibility}

Flexibility of thought has been described as important to problem solving and decision making. According to Torcivia and Gupta (2008), effective clinical reasoning requires the ability to flexibly respond to changing conditions and client needs. The category of flexibility describes student's experiences with problem solving and the ability to adjust their thinking during sessions with clients. Along with the ability to rely on their own clinical reasoning and to be able to make effective decisions, participants described their understanding of the need to adjust their thinking in the moment. Participants discussed the need to develop a plan for their client, but realize that to provide effective treatment, their plans must be fluid and be able to change with the needs

of the client. Evans et al suggests that flexibility in learning allows for greater metacognitive approaches, and a deeper ability to analyze performance (2003). While flexibility in cognition may lead to a student's increase in confusion, or feeling overwhelmed, it allows for a student to have a greater breadth and depth of problem solving capability and therefore a greater confidence.

\section{Resilience}

Throughout the data a common theme of resilience emerged. Resilience is defined as a process of adaptation to adversity and stress and is a key component of wellbeing 
(Bahadir-Yilmaz, \& Oz, 2015). Resilience has been described as a "quality necessary to succeed [for] medical and health science students" (Bahadir-Yilmaz, E. \& Oz, F., 2015). Resilience has been described as a useful skill not only when faced with extreme adversity, but also when dealing with more common stressful situations such as academic or professional transition points (Aswini \& Amrita, 2017). For purposes of review this category was used to describe opportunities for risk taking, making mistakes and having to recover and face those challenges repeatedly. Many respondents reported that learning was most impactful when they could learn from their mistakes. Students described the service learning experiences as a safe place to make mistakes. Students reported feeling as though they needed to develop trust and confidence to face a client again, even after mistakes were made.

It has been identified that health care professions must prepare students for the reality of practice. Developing resilient practitioners that can identify warning signs of burn out, identify emotional exhaustion and compassion fatigue can support practitioners in maintaining effective, client centered and occupation based practice. A study evaluating resiliency in social work students, suggests that students would benefit from opportunities to develop skills and characteristics of resiliency to combat the emotional challenges that health care professionals face. Beddoe et al (2013) suggest that "for learning to be transformative, rather than merely transmission [students of health sciences] must undertake some personal development” (p.112). Educational factors identified to help develop resilience include the ability to explore personal attributes, develop a professional identify, peer support and reflective supervision, and effective coping strategies (Beddoe, et al, 2013). Experiential learning opportunities allow instructors to provide this type of education.

As mentioned previously, this is not a static or linear model. Each of the separate parts will shift and interact in different ways at different points of the experiential 
learning experience, resulting in different constellations of relationships in particular circumstances. Different clinical challenges offer opportunities for a need to use the attributes of self-reliance, resilience and flexibility. For example, self-reliance in a clinical emergency will naturally align strongly with professional characteristics of autonomous decision-making and problem solving, and these will be influenced strongly by the prerequisite condition of independence. Other professional characteristics and prerequisite conditions may also be involved, but perhaps not as influentially. Table 2 gives possible examples of relationships among prerequisite conditions, professional characteristics, and core professional attributes, all of which influence the development of self-efficacy and clinical reasoning.

\section{Table 2}

Examples of Clinical Interactions among Attributes, Characteristics and Conditions

\begin{tabular}{|l|l|l|l|}
\hline \multicolumn{1}{|c|}{$\begin{array}{c}\text { Possible Clinical } \\
\text { Situations }\end{array}$} & \multicolumn{1}{|c|}{$\begin{array}{c}\text { Required } \\
\text { Professional } \\
\text { Attribute }\end{array}$} & $\begin{array}{c}\text { Associated } \\
\text { Professional } \\
\text { Characteristics }\end{array}$ & \multicolumn{1}{|c|}{$\begin{array}{c}\text { Influential } \\
\text { Prerequisite } \\
\text { Conditions }\end{array}$} \\
\hline $\begin{array}{l}\text { A therapist has a } \\
\text { plan to work with a } \\
\text { client in the kitchen, } \\
\text { however the kitchen } \\
\text { is no longer } \\
\text { available to use. }\end{array}$ & Flexibility & $\begin{array}{l}\text { Risk taking/ Problem } \\
\text { Solving }\end{array}$ & $\begin{array}{l}\text { Preparation/ } \\
\text { Independence }\end{array}$ \\
\hline $\begin{array}{l}\text { Clinician's initial } \\
\text { plan for treatment is } \\
\text { not effective, or } \\
\text { dismissed by client }\end{array}$ & Resilience & $\begin{array}{l}\text { Trust } \\
\text { Risk Taking }\end{array}$ & $\begin{array}{l}\text { Safe Failure/ } \\
\text { Feedback }\end{array}$ \\
\hline $\begin{array}{l}\text { The only } \\
\text { occupational } \\
\text { therapist working in } \\
\text { a rural health setting }\end{array}$ & Self-Reliance & $\begin{array}{l}\text { Valorization/ } \\
\text { Autonomous } \\
\text { Decision Making }\end{array}$ & $\begin{array}{l}\text { Perceived Value/ } \\
\text { Previous Success/ } \\
\text { Preparation }\end{array}$ \\
\hline
\end{tabular}


The examples in Table 2 are not exhaustive or exclusive, rather they serve as illustrations of the interaction between the different layers that contribute to the development of self-efficacy in an occupational therapy student. Recommendations for further exploration of the particular layers of the proposed model and its application in a variety of settings are discussed below.

\section{Recommendations}

The differences in data between the faculty and the students regarding prerequisite conditions that influence student self-efficacy contained enough variability in response to warrant further evaluation. It is believed that students and faculty do not perceive the aspects of preparation related to instructor lead opportunities in the same way. Further evaluation is required to determine which faculty led opportunities for learning and application contribute to a student's sense of self-efficacy.

It is the opinion of this researcher that faculty as mentors support the development of value of the profession through the embodiment of passion in their teaching. Through the process of teaching faculty bridge the practical knowledge of professional theory, language and approaches through stories of personal contextual application of this content. It is through this contextualized story-telling that students can begin to develop a core value structure for Occupational Therapy. However this idea was not examined in the design of this study or data collected. Further research can explore the role of faculty passion, personality and approach on the impact on the development of a student's valorization and professional self-efficacy.

Benefits of experiential learning approaches such as service learning in higher education are apparent, but many obstacles prevent this approach from being used as a consistent pedagogical approach in occupational therapy education. Common obstacles include lack of funding, time commitment, community interest, increased class sizes and scheduling difficulties (Knecht- Sabres, 2010; Horowitz, 2012; Lau, 2016). 
Future studies should explore issues related to logistical limitations for occupational therapy programs to best support programs in being able offer these types of educational opportunities.

This proposed emerging model is based upon experiential learning activities conducted in one university system. Although learning activities are designed to meet the educational standards of the occupational therapy profession, further evaluation should be conducted with other institutions to evaluate transferability of these concepts.

\section{Recommendations for Researchers}

Further research should be conducted to more specifically identify the aspects of preparation that are essential prerequisite conditions for the development of personal professional characteristics and improve the necessary core professional attributes of an occupational therapist. A variety of follow-up studies are possible. First, replication of this study in the same settings, and in other similar settings would provide a measure of reliability—revealing whether the elements identified in this study are robust, and whether there are other elements that didn't appear in research to date. Also, a factor analysis could be conducted to explore the relationships among the various elements in the model, and identify others that might emerge. This would help to strengthen the usability and transferability of the elements, and also shed light on how these constructs cluster.

A paired t-test on student confidence levels demonstrated statistical significance in this study; however, a multiple regression analysis would help reveal the comparative contributions of each element to the self-efficacy of the students. A multiple regression analysis could provide estimates of how much variance in the model can be attributed to each of the elements. One caution, though, is that multiple regressions can result in inflated $\mathrm{R}$ values if the constituent elements share some variance, which is a likelihood in this model. It is unlikely that the variables are entirely independent, so results would need 
to be viewed cautiously. Still, it would be interesting to know how much of the model's overall variance can be accounted for by the elements found in this study.

\section{Recommendations for Educators}

For educators in occupational therapy it is recommended that this proposed model be used with caution understanding the limitations inherent in an emergent model. Although this study began to reveal some of the salient characteristics of service learning that may contribute to a student's self-efficacy and improved clinical reasoning, it cannot be considered exhaustive or complete. Nor can the specific elements in the model be considered reliable at this stage of investigation. But the meta-construct of self-efficacy continues to be recognized as an important aspect of a student's development and influential to effective clinical reasoning for occupational therapists. Perhaps the aspects identified within this study can begin to contribute to future practice, and OT educators can use the constructs identified in this study to guide the development of service learning courses in OT.

\section{In Conclusion}

It has been noted in the literature that occupational therapists must establish a stronger sense of professional confidence. Glen Gillen in his 2013 Eleanor Clark Slagle address, A Fork in the Road: an Occupational Hazard comments "There have been times on our professional journey when we have begun to lose sight of and confidence in our methods" (p.641). The author comments that occupations are not used as a focus to practice in the clinics. He identifies how even within our profession we refer to our own interventions as "common place and unsophisticated". Research has supported the validity and effectiveness of our interventions, however according to Gillen, "many practitioners still see it as not as sexy and therapists seek out seemingly more sophisticated techniques"(p. 642). However, using these seemingly "more sophisticated techniques" does not guarantee these approaches are more effective, or even in line with 
our profession's philosophy. Occupational therapists lack confidence in our own approaches and modalities and envy our colleagues in other professions. Because of this envy, therapists adopt the tools and techniques of other professions they believe to be more sophisticated and move away from the central philosophy and effective tools of our own therapy. Because of this lack of confidence in our own professional capabilities, "professional blurring ensues" (642). Therefore, this lack of confidence in our professional identity that self-efficacy should be a focus of education. Self-efficacy can support effective problem solving and support the maintenance of the professional center of occupation and promote healthy professional identity development in new occupational therapy students. This research provided one place, among several, to begin to build in-roads to self-efficacious practice in occupational therapy. 


\section{References}

Alderman, K. (2004). Concepts of ability in motivation. In: M. K. Alderman (Ed.), Motivation for achievement: Possibilities for teaching and learning (2nd ed.). (pp. 66-102). Mahwah, NJ: Lawrence Erlbaum.

American Occupational Therapy Association, (2016). 2011 Accreditation Council for Occupational Therapy Education (ACOTE) standards and interpretive guide, effective July 2013. August 2016 interpretive guide version.

Retrieved from

http://www.aota.org/ /media/Corporate/Files/EducationCareers/Accredit/Stan dards/2011-Standards-and-Interpretive-Guide.pdf

American Occupational Therapy Association (2015). Code of ethics. Retrieved from https://www.aota.org/-/media/corporate/files/practice/ethics/code-ofethics.pdf

Andonian, L. (2013). Emotional Intelligence, self-efficacy and occupational therapy students' fieldwork performance. Occupational Therapy in Health Care. 27(3) 201-215.

Aswini, S., \& Amrita, D. (2017). Flourishing among post graduate students: the role of resilience, meaningfulness and grit. Indian Journal of Community Psychology, 13(1), 24-37.

Atkison, K. \& Steward, B. (1997) A longitudinal study of occupational therapy new practitioners in their first years of professional practice: preliminary findings. British Journal of Occupational Therapy, 60 (8), 338-342.

Atler, K., \& Gavin, W. (2010). Service-learning-based instruction enhances students' perceptions of their abilities to engage in evidence-based practice. Occupational Therapy in Health Care, 24(1), 23-38 
Bahadir-Yilmaz, E., \& Oz, F. (2015). The resilience levels of first year medical, dentistry, pharmacy and health sciences students. International Journal of Caring Science,. 8(2) 385-392.

Bandura, A. (1982). Self- efficacy mechanism in human agency. American Psychologist, 37, 122-147.

Bandura, A. (1997). Self-efficacy: The exercise of control. New York: Freeman.

Bazyk, S., Glorioso, M., Gordon, R., Haines, J., \& Percaciante, M. (2010) Service learning: The process of doing and becoming an occupational therapist. Occupational Therapy in Health Care, 24(2), 171-187.

Beck, A., Barnes, K. (2007). Reciprocal service learning: Texas border head start and master of occupational therapy students. Occupational Therapy in Health Care, 21(1/2). doi:10.1300/J003v21n01_02

Beddoe, L., Davys, A., \& Adamson, C. (2013). Educating resilient practitioners. Social Work Education. 32(1). 100-117.

Bernadowski, P., \& Del Greco. (2013). Improving preservice teachers' self-efficacy. International Journal of Instruction, 6(2), 67-86.

Brady- AMoon, P. \& Furetes, J., (2011) Self efficacy, self rated abilities, adjustment and academic performance. Journal of Counseling and Development, 89(4). 431-438.

Brown, D., and Wise, H. (2007). Service learning to facilitate attainment of professional practice expectations in prevention and health promotion. Journal of Physical Therapy Education, 21, 59-64.

Bush, J., Powell, N. \& Herzberg, G. (1993). Career self efficacy in occupational therapy practice. American Journal of Occupational Therapy, 47(10), 927933. 
Carmeli, A., \& Josman, Z. E. (2006). The relationship among emotional intelligence, task performance, and organizational citizenship behaviors. Human Performance, 19(4), 403-419.

Caruso, D. (1999). Applying the ability model of emotional intelligence to the world of work. Retrieved from http://www.leadershipcoachacademy.com/handouts/EQ Week1 Article WorldofWork.doc

Coates, G., \& Crist, P. (2004). Brief or new: Professional development of fieldwork students: Occupational adaptation, clinical reasoning, and client-centeredness. Occupational Therapy in Health Care, 18(1/2), 39-47.

Cocker, P., (2010). Effects of an experiential learning program on the clinical reasoning and critical thinking skills of occupational therapy students. Journal of Allied Health, 39(4), 280-286.

Cone, N. (2009). Community based service learning as a source of personal self efficacy: Preparing preservice elementary teachers to teach science for diversity. School Science and Mathematics, 109(1). 20-30.

Denton, J. M., Esparza, S., Fike, D. S., Gonzalez, J., \& Lundquist Denton, M. (2016). Improvements in cultural competence through classroom and local crosscultural service-learning activities. Journal of Physical Therapy Education, 30(2), 6-13. Retrieved from http://prxusa.lirn.net/login?url=http://search.ebscohost.com/login.aspx?direct $=$ true $\& \mathrm{db}=\mathrm{ccm} \& \mathrm{AN}=115107391 \&$ site $=$ eds-live

Derdall, M., Olson, P., Janzen, W., \& Warren, S. (2002). Development of a questionnaire to examine confidence of occupational therapy students during fieldwork experiences. Canadian Journal of Occupational Therapy, 69(1) 4956. 
Evans, C., Kirby, J. \&Fabrigar, L. (2003). Approaches to learning, need for cognition and strategic flexibility among university students. British Journal of Educational Psychology, 73, 507-528.

Eyler, J. (2002), Reflection: Linking service and learning_-Linking students and communities. Journal of Social Issues, 58, 517-534.

Eyler, J. \& Giles, D. (1999). Where is the learning in service learning? Journal of Higher Education, 72(2), 256-258.

Facione, N., Facione, P. (2008) Critical thinking and clinical judgment. Critical thinking and clinical reasoning in the health sciences: A teaching anthology. Millbrae CA: California Academic Press.

Fleming, M. (1991) Clinical reasoning in medicine compared with clinical reasoning in occupational therapy. American Journal of Occupational Therapy, 45(11), 988- 996.

Fleming, M. (1991). The therapist with the three-track mind. American Journal of Occupational Therapy, 45(11), 1007-1014.

Flinn, S., K., Loos, A., Teaford, M., Clark, K., \& Szcucs, K.(2009). Helping hands for healthy living: A collaborative service learning project with occupational and physical therapy students. Occupational Therapy in Health Care, 23(2), 146-157 .

Fondiller, E., Rosage,L., \& Neuhaus, B. (1990). Values influencing clinical reasoning in occupational therapy: An exploratory study. The Occupational Therapy Journal of Research, 10(1), 41-55.

Fredholm, A., Savin-Badin, M., Henningsohn, L., \& Silen, C. (2015). Autonomy as both challenge and development in clinical education. Learning, Culture and Social Interactions, 5, 20-27. 
Gardner, H. (2011). Frames of mind: The theory of multiple intelligences. New York: Basic Books.

George, J. (2000). Emotions and leadership: The role of emotional intelligence. Human Relations, 53(8), 1027-1055.

Gillen, G. (2013). A fork in the road: An occupational hazard? (Eleanor Clark Slagle Lecture). American Journal of Occupational Therapy, 67, 641-652.

Gitlow, L., \& Flecky, K. (2005). Integrating disability studies concepts into occupational therapy education using service learning. American Journal of Occupational Therapy, 59, 546-553.

Griffiths, Y., \& Ursick, K. (2003). Active learning and occupational therapy education. OT Practice, 17, 1-3

Higgs, J., \& Jones, M. (2000). Clinical reasoning in the health professions. In: J. Higgs \& M. Jones (Eds.), Clinical reasoning in the health professions (pp. 314). Oxford: Butterworth-Heinemann.

Hoffman, S. \& Silverberg, S. (2015). Training the next generation of global health advocates through experiential education: A mixed methods case study evaluation. Canadian Journal of Public Health, 106(6), e442-e449.

Hooper, B., \& Mitcham, M. (2004). Teaching to promote graduate, occupationcentered education. OT Practice, 9, 13-17.

Horowotz, B. (2012). Service learning and occupational therapy education: preparing students for community practice. Education Special Interest Section Quarterly, 22(2), 1-4.

Jacoby, B. (2003). Building partnerships for service-learning. San Francisco CA: Jossey-Bass.

Johnson,R., Onwuegbuzie, A., \& Turner, L. (2007) Toward a definition of mixed method research. Journal of Mixed Methods Research. 1(2), 112-133. 
Joint Educational Project (2005). Service-learning. Retrieved from

https://communities.usc.edu/joint-educational-project-jep-service-learning/

Kelly, S. \& Miller, E. (2008). Education for service: Development of a service learning course. Journal of Physical Therapy Education, 22(1), 33-41.

King, P. (1992). How do we know? Why do we believe? Liberal Education, 78(1), 2-

9.

Knecht- Sabres, L., Kovic, M., Wallingford, M., St. Amand, L. (2013). Preparing occupational therapy students for the complexities of clinical practice. The Open Journal of Occupational Therapy 1(3). 4.

Koenig, K., Johnson, C., Morano, C., \& Ducette, J. (2003). Development and validation of a professional behavior assessment. Journal of Allied Health, $32(2), 86-91$.

Kolb, D. A. (1984). Experiential learning: Experience as the source of learning and development. New Jersey: Prentice Hall.

Kramer, P., Ideishi, R., Kearney, P., Cohen, M., Ames, J., Shea, G., et al. (2007). Achieving curricular themes through learner-centered teaching. Occupational Therapy in Health Care, 21(1/2), 185- 198.

Lau, C. (2016). Impact of a child based health promotion service learning project on the growth of occupational therapy students. The American Journal of Occupational Therapy, 70(5), 1-10.

Langstraat, L., \& Bowdon, M. (2011). Service learning and critical emotion studies: On the perils of empathy and the politics of compassion. Michigan Journal of Community Service Learning,17(2), 5-14.

Law, M. (2010). Learning by doing: Creating knowledge for occupational therapy. World Federation of Occupational Therapy Bulletin, 62, 12-18. 
Lopes, P. N., Grewal, D., Kadis, J., Gall, M., \& Salovey, P. (2006). Evidence that emotional intelligence is related to job performance and affect and attitudes at work. Psicothema, 18, 132-138.

Mattingly C., \&Fleming, M. (1994). Clinical reasoning: Forms of inquiry in a therapeutic practice. Philadelphia: FA Davis.

Mattingly, C. (1991). What is clinical reasoning? American Journal of Occupational Therapy, 45(11), 979-986.

McDonnell, A., Lloyd Jones, M., \& Reed, S. (2000). Practical considerations in case study research: The relationship between methodology and process. Journal of Advanced Nursing, 32(2), 383-390.

Mitcham, M. (2014). Education as engine (Eleanor Clark Slagle Lecture). American Journal of Occupational Therapy, 68, 636-648.

Narsavage G., Lindell, D., Chen, Y., Savrin, C., \& Duffy, E. (2002). A community engagement initiative: Service-learning in graduate nursing education. Journal of Nursing Education, 41, 457-461.

Olivier, M., Oosthuizen, L., \& Casteleijn, D. (2007). Occupational therapy students' contribution towards enabling potential in a semi-rural community. Work, 29, 63-68.

Opacic, D. (20 03). The relationship between self-efficacy and student physician assistant clinical performance. Journal of Allied Health, 32(3), 158-166.

Paavola, S., Hakkarainen, K. (2005). The knowledge creation metaphor - An emergent epistemological approach to learning. Science and Education, 14, $535-557$

Peganoff , O’Brien, S., \& D’Amico, M.L. (2004). Scholarship of engagement and service learning: A natural fit in occupational therapy curricula. American 
Occupational Therapy Association Education Special Interest Section

Quarterly, 14, 1-3.

Perrin, J. (2014). Features of engaging and empowering experiential learning programs for college students. Journal of University Teaching and Learning Practice, 11(2), 1-12.

Portney, L., \&Applebaum, D. (2006). Integrating objectives for clinical education, research, and service learning into community health promotion projects. Journal of Physical Therapy Education, 20, 18-24.

Reising, D., Allen, P \& Hall, S. (2006). Student and community outcomes in service learning: Part 1- student perceptions. Journal of Nursing Education, 45(12), 512-515.

Reising, D., Shea, R., Allen, P., Laux, M., Hensel, D., \& Watts, P. (2008). Using service-learning to develop health promotion and research skills in nursing students. International Journal of Nursing Education Scholarship, 5(1), 115.

Richardson, M., Abraham, C. \& Bond, R. (2012). Psychological correlates of university students' academic performance: A systematic review and metaanalysis. Psychological Bulletin, 138, 353-387.

Rodger, S., Fitzgerald, C., Davila, W., Millar, F., \& Allison, H. (2011). What makes a quality occupational therapy practice placement? Students' and practice educators' perspectives. Australian Occupational Therapy Journal, 58(3), $195-202$.

Romani, W. \& Holbert, L. (2007). Wellness service learning project improves the perception of professional empowerment in physical therapist students. Journal of Physical Therapy, 21(2), 73-78. 
Rosete, D., \& Ciarrochi, J. (2005). Emotional intelligence and its relationship to workplace performance outcomes of leadership effectiveness. Leadership \& Organization Development Journal, 26(5), 388-399.

Schell B. (2003). Clinical Reasoning: The basis of practice. In E.B. Crepeau, E.S. Cohn, \& B.A.Schell (Eds.) Willard and Spackman's Occupational Therapy (10th ed.) (pp. 131-139). Philadelphia: Lippincott Williams \& Wilkins.

Scaffa, M.,\& Wooster,D. (2004). Effects of problem- based learning on clinical reasoning in occupational therapy. American Journal of Occupational Therapy, 58(3): 333-336.

Schaber, P., Marsh, L., \& Wilcox, K. J., (2012). Relational learning and active engagement in occupational therapy professional education. In N.L. Chick, A. Haynie, \& R.A.R. Gurung (Eds.), Exploring more signature pedagogies: Approaches to reaching disciplinary habits of mind (pp. 188-202). Sterling, VA: Stylus.

Schell, B. \& Cervero R. (1993). Clinical reasoning in occupational therapy: and integrative review. American Journal of Occupational therapy, 47, 605-610.

Schell B. \&Schell J. (2008). Clinical and professional reasoning in occupational therapy. Baltimore; Lippincott Williams \&Wilkins.

Schunk, D.H. (2003). Self efficacy for reading and writing: influences of modeling, goal setting and self evaluation. Reading and Writing Quarterly, 19, 159-172.

Schunk, D. H. (2004). Social cognitive theory. In: D. H. Schunk (Ed.), Learning theories: An educational perspective (4th ed) (pp. 83-135). Upper Saddle River, NJ: Merrill Prentice Hall.

Schunk, D., Pajares, F.(1993) Development of academic self efficacy. In A. Wigfield \& J.S. Eccles (Eds.), Development of achievement motivation (pp. 1-27). San Diego: Academic Press. 
Self Reliance (2017) In Merriam- Webster. Com. https://www.merriamwebster.com/dictionary/self-reliance.

Shulman, L. (2005). Signature pedagogies in the professions. Daedalus, 134, 52-59. Statistical Package for Social Sciences for Windows [Computer Software]. (2015). Chicago IL: SPSS Inc.

Steinke, P., \& Fitch, P. (2007). Assessing service-learning. Research \& Practice in Assessment, 1(2), 1-8.

Steinke, P. \& Fitch, P. (2014). Using goal-based learning to understand why servicelearning improves cognitive outcomes, Currents in Teaching and Learning, $7(1)$.

Swars, S., Hart, L.C., Smith, S. Z. Smith, M.E., \& Tolar, T. (2007). A longitudinal study of elementary pre-service teachers' mathematics beliefs and content knowledge. School Science and Mathematics, 107(8), 325-335.

Trainor, J. (2008). Rethinking racism: Emotion, persuasion, and literacy education in an all-white high school. Carbondale, IL: Southern Illinois University Press.

Torcivia, E., \& Gupta, J. (2008). Designing learning experiences that lead to critical thinking and enhanced clinical reasoning. OT Practice, 13(5) CE1-CE-8.

Townsend, E. \& Whiteford, G. (2005). A participatory occupational justice framework. In F. Kronenberg, S. Simo-Algado, \& N. Pollard (Eds.) Occupational therapy without borders: Learning from the spirit of survivors (pp. 110-126). New York, NY: Elsevier Churchill Livingstone.

Tornebohm, H.(1991). What is worth knowing in occupational therapy? American Journal of Occupational Therapy, 45, 451-454.

University of St. Augustine for Health Sciences (2016). Course Catalog. Retrieved from https://www.usa.edu/p7-297-University-Catalog.aspx 
Utsey, C. J. (2006). Differences in motivational beliefs and learning strategies of physical therapist students in classroom and clinical settings. Houston, TX: University of Houston. ProQuest Dissertations and Theses, 128-128.

Vax, S., Schreuer, N., \& Sachs, D. (2012). Work-related self-efficacy of occupational therapists in mental health. Scandinavian Journal of Occupational Therapy, $19(1), 42-48$.

Velde, B., Wittman, P., \& Vos, P. (2006). Development of critical thinking in occupational therapy students. Occupational Therapy International, 13(1), 49-60.

Zoreck, J., Sprague, J. \& Popovich, N. (2010). Bulimic learning. American Journal of Pharmaceutical Education, 74(8). 157-160

Zimmerman, B. (2000). Self efficacy: An essential motive to learn. Contemporary Educational Psychology, 25. 82-91. 
Appendix A: Participant Informed Consent 


\title{
IRB Informed Consent Form, IRB \#
}

Title: Employing service learning to promote student self-efficacy in occupational therapy education.

\author{
Principal Investigator(s) \\ Erin Schwier \\ eschwier@usa.edu \\ Co-investigator(s) \\ Judith Olson \\ Jolson60@gmail.com \\ Anne Hull \\ ahull@usa.edu
}

\section{Description of the Study:}

This study has been designed to assess student level of confidence in clinical settings before and after service learning projects. It will also attempt to identify how participation in service learning contributes to your level of confidence.

As a participant in the study you will be asked to fill out a survey related to how confident you feel in clinical settings both before and after your mock clinic course. All participants will be assigned a non-identifying number to use on completion of the questionnaires, this number will be used to be able to compare results of pre and post test scores.

The person assigned to data entry will not have the students' identities, and confidentiality of responses will be maintained. Your name or demographic information will never be used in any reporting of the data. All findings will be reported as group data. The results of these surveys will not be considered as a part of your course grade.

Although the study will not differentiate between the response of "male" and "female" participants, the "gender" category has been included in the event that this information may be useful in future studies. Also, the "age" category may yield significant data regarding the development of confidence as related to years of "life experience".

\section{Benefits and Risks to the Participant:}

There are no identified benefits or risks associated with participation in this survey.

Confidentiality: All information obtained in this study is strictly confidential unless disclosure is required by law. 
Participation in this study is voluntary, and you have the right to withdraw at any time without consequences.

Your consent is required before you can participate. See signature statement below.

\section{Investigator's claim:}

I have explained to the purpose of the research study, the procedures required, and the possible risks and benefits to the best of my ability.

Investigator's signature: Date:

Investigator's printed name: 


\section{Participant's claim:}

I have read this consent form (or it has been read to me) and I fully understand the contents of this document and voluntarily consent to participate. All of my questions concerning this research have been answered. If I have any questions in the future about this study, the investigator listed above or his/her staff will answer them. A copy of this form has been given to me.

Participant's signature

Date

Participant's printed name

Witness's signature

Date

Witness's printed name 
Appendix B: Internal Review Board Approval 


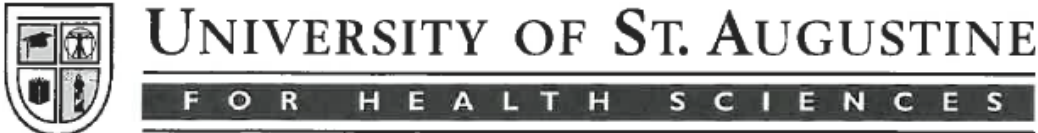

November 28, 2016

Erin Schwier OTD OTR/ L

Program Director/ Assistant Professor

University of St. Augustine, San Marcos

(760) 591-3012 ext. 2446

eschwier@usa.edu

RE: UR-1114-030 "Employing service learning to promote student self-efficacy in occupational therapy education."

Dear Dr. Schwier,

The Chair of the Institutional Review Board (IRB), responsible for the review of research involving human subjects, has reviewed your edited proposal, noted the revisions provided by you upon the reviewers' request and approved the revised project referenced above. Approval for the project will be for one year, starting November 28, 2016.

If a University of St. Augustine For Health Sciences faculty member or student leaves the University prior to completion of a USAHS IRB-approved study, the study may be continued until expiration of that IRB approval. The IRB approval will expire on November 28, 2017. Any unanticipated problems involving risks to human subjects or serious adverse effects must be promptly reported to the IRB.

This approval is granted with the understanding that no changes may be made in the procedures to be followed, nor in the consent form(s) to be used; until after such modifications have been submitted to the IRB for review and approval. Please be sure your consent form includes the IRB contact name and telephone (Dr. M.E. Miller, IRB Chair, University of St. Augustine for Health Sciences Institutional Review Board, 760-591-3012 x2417,mmiller@usa.edu). Researchers must retain a copy of the signed consent form in their files for three years following completion of the project and must provide a copy of the consent form to the subject(s)

Prior to the expiration of this approval, you will receive notification of the need for updated information to be used for the project's continuing review. When project is completed, please notify the IRB in writing. Thank you.

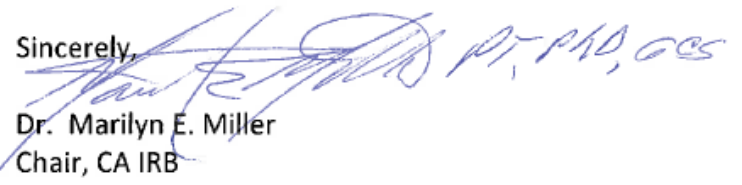

Co Investigators: J. Olsen
A. Hull

1 UNIVERSITY BOULEVARD - ST. AUGUSTINE, FL 32086-5783 - (904) 826-0084 - FAX (904) 826-0085 - WeBsite: www.usa.edu 
Appendix C: Student Confidence Pre Test 


\section{O.T. Students' Level of Confidence}

(Derdall et. al, 2002)

Pre Test

\section{Questions:}

Please respond by circling the appropriate number next to the question.

$\underline{\text { Scoring }}$

A. Communication: "I am confident that I can ...." Strongly Disagree Strongly Agree

1. Interact with clients. $\quad \begin{array}{lllll}1 & 2 & 3 & 4\end{array}$

5

2. Communicate assertively with team members. $\quad \begin{array}{lllll}1 & 2 & 3 & 4\end{array}$

5

3. Develop goals with a client. $\quad \begin{array}{lllll}1 & 2 & 3 & 4\end{array}$

5 Explain the role of OT to clients/families.

4. Explain the role of OT to clients/families. $\quad \begin{array}{lllll}2 & 1 & 2 & 3 & 4\end{array}$

5. Prepare effective written reports. $\quad \begin{array}{lllll}1 & 2 & 3 & 4\end{array}$

5

6. Prepare and deliver effective verbal presentations. $\begin{array}{llllll}1 & 2 & 3 & 4\end{array}$

5 . Handle disagreements that may arise $\quad 1 \quad 3$

7. Handle disagreements that may arise. $\quad \begin{array}{lllll}1 & 2 & 3 & 4\end{array}$

5

$\begin{array}{lllllll}\text { 8. Collaborate with other therapists. } & 1 & 2 & 3 & 4\end{array}$ 5

B. Adaptability: "I am confident that I can ...."

5

9. Adjust to a new clinical setting. $\quad \begin{array}{lllll}1 & 2 & 3 & 4\end{array}$

10. Use alternate assessment strategies as needed. $\quad \begin{array}{llllll}1 & 2 & 3 & 4\end{array}$

5

11. Use alternate interventions as indicated. $\quad \begin{array}{lllll}1 & 2 & 3 & 4\end{array}$

12. Re-organize my time effectively when there are $\quad \begin{array}{lllll}1 & 2 & 3 & 4\end{array}$ unexpected changes in my schedule.

13. Handle challenges presented $\quad \begin{array}{lllll}1 & 2 & 3 & 4\end{array}$ 
C. Innovation: "I am confident that I can ...."

14. Use my own ideas in clinical practice. $\quad \begin{array}{lllll}1 & 2 & 3 & 4\end{array}$

5

15. Use problem-solving techniques. $\quad \begin{array}{lllll}1 & 2 & 3 & 4\end{array}$

5

16. Take opportunities to use initiative $\quad \begin{array}{lllll}1 & 2 & 3 & 4\end{array}$

5

5

17. Make suggestions to my supervisor. $\quad \begin{array}{lllll}1 & 2 & 3 & 4\end{array}$

18. Seek out information from appropriate resources. $\begin{array}{lllll}1 & 2 & 3 & 4\end{array}$ 5 


\section{$\underline{\text { Scoring }}$}

D. Risk Taking: "I am confident that I can ...."

Strongly Disagree $\quad$ Strongly Agree

19. Use techniques which I have practiced.

12

23

4

20. Use techniques which I have observed.

12

4 5

21. Use techniques which I have not practiced/observed $\begin{array}{llll}1 & 2 & 3 & 4\end{array}$ 5 (after discussing with my supervisor).

22. Learn from my mistakes.

$\begin{array}{llll}1 & 2 & 3 & 4\end{array}$
5

E. Supervision: "I am confident that I can ...."

23. Function in the student-supervisor relationship. $\quad \begin{array}{lllll}1 & 2 & 3 & 4\end{array}$ 5

24. Seek feedback from my supervisor, clients and $\quad \begin{array}{lllll}1 & 2 & 3 & 4\end{array}$ 5 colleagues.

25. Accept direction and constructive feedback 5 provided.

26. Delegate tasks to support staff. 5

27. Decide when to collaborate and when to be 5 self-directed.

F. Clinical Practice: "I am confident that I can ...."

28. Apply the role of OT in clinical practice. 5

29. Supervise client programs effectively. 5

30. Work on a team when roles overlap.

(1)

2

$3 \quad 4$
5

31. Handle considerable autonomy in my work. 5

32. Work in a non-traditional setting. 5

$\begin{array}{llll}1 & 2 & 3 & 4\end{array}$

$\begin{array}{llll}1 & 2 & 3 & 4\end{array}$


33. Analyze activity.

123

4

5

34. Select appropriate frames of reference. $\quad \begin{array}{lllll}1 & 2 & 3 & 4\end{array}$ 5

35. Select appropriate assessments.

$\begin{array}{llll}1 & 2 & 3 & 4\end{array}$
5

36. Administer assessments.

$\begin{array}{llll}1 & 2 & 3 & 4\end{array}$
5

37. Analyze findings and establish priorities. $\quad \begin{array}{llll}1 & 2 & 3 & 4\end{array}$ 5

38. Plan and provide intervention independently. $\quad \begin{array}{lllll}1 & 2 & 3 & 4\end{array}$ 5

39. Make recommendations for intervention \& follow-up. $1 \quad 2 \quad 3 \quad 4$ 5

40. Perform discharge planning. 5

41. Evaluate programs. 5

\section{Demographic Data}

Gender:

Male

Female

Other
Age Category:

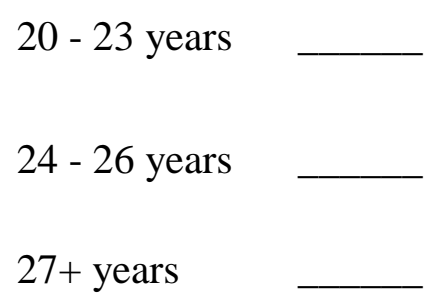


Appendix D: Student Confidence Post Test 


\section{O.T. Students' Level of Confidence}

(Derdall et. al, 2002)

Post Test

\section{Questions:}

Please respond by circling the appropriate number next to the question.

Scoring

A. Communication: "I am confident that I can ...." Strongly Disagree Strongly Agree

1. Interact with clients.

5

2. Communicate assertively with team members. $\quad \begin{array}{llllll}1 & 2 & 3 & 4\end{array}$

5

3. Develop goals with a client. $\quad \begin{array}{lllll}1 & 2 & 3 & 4\end{array}$ 5

4. Explain the role of OT to clients/families. $\quad \begin{array}{lllll}1 & 2 & 3 & 4\end{array}$ 5

5. Prepare effective written reports. $\quad \begin{array}{lllll}1 & 2 & 3 & 4\end{array}$

5

6. Prepare and deliver effective verbal presentations. $\begin{array}{llllll}1 & 2 & 3 & 4\end{array}$ 5

7. Handle disagreements that may arise. $\quad \begin{array}{llllll} & 1 & 2 & 3 & 4\end{array}$ 5

8. Collaborate with other therapists.

$\begin{array}{lllll}1 & 2 & 3 & 4\end{array}$
5

B. Adaptability: "I am confident that I can ...."

5

9. Adjust to a new clinical setting. $\quad \begin{array}{llllll}1 & 2 & 3 & 4\end{array}$

10. Use alternate assessment strategies as needed. $\quad \begin{array}{lllll}1 & 2 & 3 & 4\end{array}$

5

11. Use alternate interventions as indicated. $\quad \begin{array}{lllll}1 & 2 & 3 & 4\end{array}$

12. Re-organize my time effectively when there are $\quad \begin{array}{lllll}1 & 2 & 3 & 4\end{array}$ unexpected changes in my schedule.

13. Handle challenges presented $\quad \begin{array}{llll}1 & 2 & 3 & 4\end{array}$ 
C. Innovation: "I am confident that I can ...."

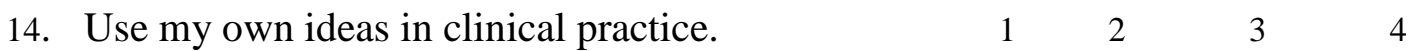

5

15. Use problem-solving techniques. $\quad 1 \quad \begin{array}{llll}2 & 3 & 4\end{array}$

5

16. Take opportunities to use initiative $\quad \begin{array}{llllll}1 & 2 & 3 & 4\end{array}$

5

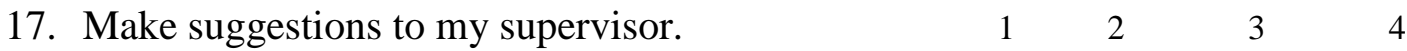

5

18. Seek out information from appropriate resources. $\begin{array}{llllll}1 & 2 & 3 & 4\end{array}$ 5 


\section{$\underline{\text { Scoring }}$}

D. Risk Taking: "I am confident that I can ...."

Strongly Disagree $\quad$ Strongly Agree

19. Use techniques which I have practiced.

12

23

4

20. Use techniques which I have observed.

12

4 5

21. Use techniques which I have not practiced/observed $\begin{array}{llll}1 & 2 & 3 & 4\end{array}$ 5 (after discussing with my supervisor).

22. Learn from my mistakes.

$\begin{array}{llll}1 & 2 & 3 & 4\end{array}$
5

E. Supervision: "I am confident that I can ...."

23. Function in the student-supervisor relationship. $\quad \begin{array}{lllll}1 & 2 & 3 & 4\end{array}$ 5

24. Seek feedback from my supervisor, clients and $\quad \begin{array}{lllll}1 & 2 & 3 & 4\end{array}$ 5 colleagues.

25. Accept direction and constructive feedback 5 provided.

26. Delegate tasks to support staff. 5

27. Decide when to collaborate and when to be 5 self-directed.

F. Clinical Practice: "I am confident that I can ...."

28. Apply the role of OT in clinical practice. 5

29. Supervise client programs effectively. 5

30. Work on a team when roles overlap.

(1)

2

$3 \quad 4$
5

31. Handle considerable autonomy in my work. 5

32. Work in a non-traditional setting. 5

$\begin{array}{llll}1 & 2 & 3 & 4\end{array}$

$\begin{array}{llll}1 & 2 & 3 & 4\end{array}$

G. Professional Competence: "I am confident that I can ...." 
33. Analyze activity.

123

4

5

34. Select appropriate frames of reference. $\quad \begin{array}{lllll}1 & 2 & 3 & 4\end{array}$ 5

35. Select appropriate assessments. $\quad \begin{array}{lllll}1 & 2 & 3 & 4\end{array}$

5

36. Administer assessments. $\quad \begin{array}{lllll}1 & 2 & 3 & 4\end{array}$

37. Analyze findings and establish priorities.

37. Analyze findings and establish priorities. $\quad \begin{array}{llll}1 & 2 & 3 & 4\end{array}$

38. Plan and provide intervention independently. $\begin{array}{llllll}1 & 2 & 3 & 4\end{array}$

5

39. Make recommendations for intervention \& follow-up. $1 \quad 2 \quad 3 \quad 4$ 5

40. Perform discharge planning. $\quad \begin{array}{lllll}1 & 2 & 3 & 4\end{array}$ 5

41. Evaluate programs. $\quad \begin{array}{lllll} & 1 & 2 & 3 & 4\end{array}$

\section{Demographic Data}

Gender:

Male
Female
Other

Age Category:

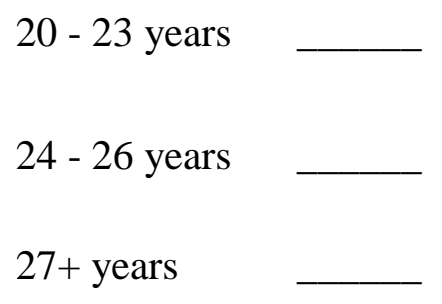

\section{Posttest Reflective questions:}

How did the experiences in Mock Clinic impact your development as an OT student? 
What aspects of this experience contributed to your learning or feelings of confidence?

Appendix E: Permission to Use Confidence Questionnaire 
From: Michele Derdall [mailto:derdall@ualberta.ca]

Sent: Friday, June 16, 2017 8:06 AM

To: Erin Schwier<ESchwier@usa.edu>

Subject: Re: Confidence Questionnaire

Hi Erin,

I'm glad you found the tool useful! I'd be happy to see your results if convenient.

You have my permission to use the Student Confidence Questionnaire for your research.

Michele

On Thu, Jun 15, 2017 at 10:01 PM, Erin Schwier<ESchwier@usa.edu > wrote:

Hi Michelle,

Well, it has been about a year since I last wrote from the looks of it, and I am actually in the home stretch of completing my dissertation. I had included this email in my submission to the team as your permission to use the self-confidence questionnaire.

I did, in fact, use it- with great success to evaluate change after engaging in a service learning project. I will be happy to share my findings with you if you would like. The committee asks that I reach out and see if I can get more definitive permission from you to use the questionnaire. Email is fine, nothing formal will be necessary, just a message stating that I do in fact have your permission to use this for my study. Thank you so much for first writing such a great tool, and then also for allowing me to use it.

Best,

Erin

Erin Schwier

Erin Schwier OTD OTR/L

Program Director/ Assistant Professor

Occupational Therapy

University of St. Augustine for Health Sciences

eschwier@usa.edu 
Appendix F: Instructor Reflective Questions 
Describe the experiential learning approaches used in Mock Clinic on your campus.

How did the experiences in Mock Clinic impact the development of the OT students?

What aspects of this experience contributed to the students learning or feelings of confidence? 